\title{
Regio- and Stereoselective Synthesis of a New Series of Spirooxindole Pyrrolidine Grafted Thiochromene Scaffolds as Potential Anticancer Agents
}

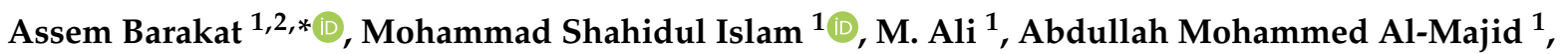 \\ Saeed Alshahrani ${ }^{1}$, Abdullah Saleh Alamary ${ }^{1}$, Sammer Yousuf ${ }^{3}$ and M. Iqbal Choudhary ${ }^{3}$ \\ 1 Department of Chemistry, College of Science, King Saud University, P.O. Box 2455, \\ Riyadh 11451, Saudi Arabia; mislam@ksu.edu.sa (M.S.I.); maly.c@ksu.edu.sa (M.A.); \\ amajid@ksu.edu.sa (A.M.A.-M.); chemistry99y@gmail.com or 436106738@ksu.edu.sa (S.A.); \\ alamary1401@yahoo.com or 436106737@ksu.edu.sa (A.S.A.) \\ 2 Department of Chemistry, Faculty of Science, Alexandria University, P.O. Box 426 Ibrahimia, \\ Alexandria 21321, Egypt \\ 3 H.E.J. Research Institute of Chemistry, International Center for Chemical and Biological Sciences, \\ University of Karachi, Karachi 75270, Pakistan; dr.sammer.yousuf@gmail.com or \\ sammer.yousuf@iccs.edu (S.Y.); iqbal.choudhary@iccs.edu (M.I.C.) \\ * Correspondence: ambarakat@ksu.edu.sa; Tel.: +966-11467-5901; Fax: +966-11467-5992
}

Citation: Barakat, A.; Islam, M.S.; Ali, M.; Al-Majid, A.M.; Alshahrani, S.; Alamary, A.S.; Yousuf, S.; Choudhary, M.I. Regio- and Stereoselective Synthesis of a New Series of Spirooxindole Pyrrolidine Grafted Thiochromene Scaffolds as Potential Anticancer Agents. Symmetry 2021, 13, 1426. https:// doi.org/10.3390/sym13081426

Academic Editors: George Papageorgiou and Miroslav Miletín

Received: 25 June 2021

Accepted: 28 July 2021

Published: 4 August 2021

Publisher's Note: MDPI stays neutral with regard to jurisdictional claims in published maps and institutional affiliations.

Copyright: (c) 2021 by the authors. Licensee MDPI, Basel, Switzerland. This article is an open access article distributed under the terms and conditions of the Creative Commons Attribution (CC BY) license (https:// creativecommons.org/licenses/by/ $4.0 /)$.

\begin{abstract}
A series of new spiro-heterocycles engrafted spirooxindole/pyrrolidine/thiochromene scaffolds was synthesized by the three-component 1,3-dipolar cycloaddition reactions in a fully controlled regio- and stereo-selective fashion. Condensation of several substituted isatin derivatives with L-proline generated the azomethine ylides which subsequently reacted with chalcones based thiochromene scaffold, and finally afforded the target spiro-compounds. This simple protocol furnished a structurally complex, biologically relevant spiro-heterocycles in good yields through a one-pot process. All synthesized chalcone-based thiochromene, along with the spirooxindole/pyrrolidine/thiochromene scaffolds, were tested for their anticancer activity against four cancer cell lines (PC3, HeLa, MCF-7, and MDA-MB231). Toxicity of these compounds was also evaluated against human fibroblast BJ cell line, and they appeared to be not cytotoxic. For the prostate cancer (PC3) cell line, the most active hybrid, among synthesized series, was compound (7f, $\left.\mathrm{IC}_{50}=8.7 \pm 0.7 \mu \mathrm{M}\right)$. The most potent spirooxindole/pyrrolidine/thiochromene hybrid against cervical (HeLa) cancer cells was compound $\left(7 \mathbf{k}, \mathrm{IC}_{50}=8.4 \pm 0.5 \mu \mathrm{M}\right)$ having chlorine and $p$-trifluoromethyl substituents attached to phenyl rings. Finally, against the MCF-7 and MDA-MB231 breast cancer cell lines, compound (7d) was the most active member of this series $\left(\mathrm{IC}_{50}=7.36 \pm 0.37\right.$, and $9.44 \pm 0.32 \mu \mathrm{M}$, respectively).
\end{abstract}

Keywords: spirooxindole; pyrrolidine; thiochromene; 1,3-dipolar cycloaddition reaction; anticancer activity

\section{Introductiong}

The three-component 1,3-dipolar cycloaddition reaction is a powerful methodology for robust synthesis of structurally complex and biologically active spiro-heterocycles [1] This method has been widely used for the synthesis of many compounds, engrafted spiro-centers, with diverse biological activities, and suitability to the integral structure rigidity. Spirooxindole/pyrrolidine heterocycles are ubiquitous in many natural products, such as tryprostatins A and B [2,3], formosanine [4], coerulescine [5], elacomine [6], horsfiline [7], pteropodine, isopteropodine [8], alstonisine [9], rychno-phyilline [10], strychnofoline [11], and other many alkaloids (Figure 1). These spiro-heterocycles with oxindole and pyrrolidine scaffolds possesses wide spectrum pharmacological activities, such as 
antimycobacterial [12,13], antimicrobial [14], local anesthetic [15], and anticancer [16-23] agents, and in acetylcholinesterase inhibition [24,25].<smiles>COc1ccc2c(c1)[C@@]1(CCN(C)C1)C(=O)N2</smiles>

(-)-Horsfiline<smiles>CN1CCC2(CC1)C(=O)Nc1ccccc12</smiles>

Coerulescine<smiles>CC(C)C1N(C)CC[C@]12C(=O)Nc1cc(O)ccc12</smiles>

(+)-Elacomine<smiles>CC(C)(C)CC1N[C@H](C(=O)N[C@H]2C[C@@](C)(O)C2)[C@@H](c2cccc(Cl)c2F)[C@]12C(=O)Nc1cc(Cl)ccc12</smiles>

MI-888

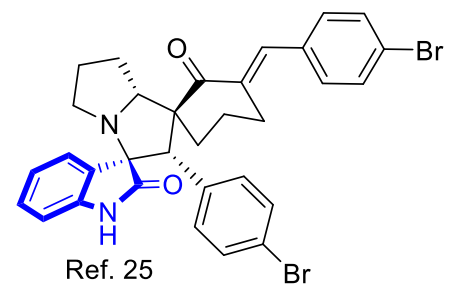<smiles>[R]c1ccc2c(c1)NC(=O)C21CCC2C(CN3CCCC3C3=CC(C)=CCN32)C1</smiles>

Spirotryprostatins $\mathrm{A} ; \mathrm{R}=\mathrm{OCH}_{3}$ Spirotryprostatins $B ; \mathrm{R}=\mathrm{H}$

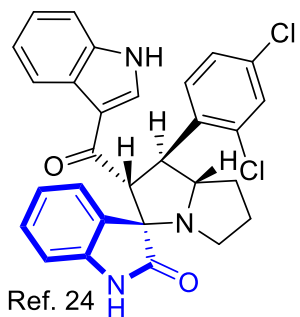<smiles>[R]c1ccc(NC(=S)Nc2ccc3c(c2)C(C)(C)CC(C)(C)S3)cc1</smiles>

Anti-cancer $\mathrm{R}=\mathrm{CO}_{2} \mathrm{Et}, \mathrm{NO}_{2}$<smiles>CN(CCc1cccs1)CC1CCSc2ccccc21</smiles>

a2-Adrenergic antagonist<smiles>CN(CCC(F)(F)F)CC1c2ccc(O)cc2SC[C@]1(C)c1ccc(O)cc1</smiles>

Estrogen recpetor downregulator<smiles>O=C(O)c1ccc2sc(C3CC4C5CC3CC4C5)cc(=O)c2c1</smiles>

Steroid sulfatase inhibitor

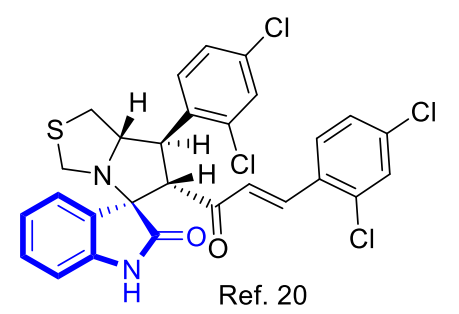<smiles>[R]c1ccc(C(=O)[C@H]2[C@H](C3=C(Cl)c4ccccc4SC3)[C@@H]3CCCN3[C@@]23C(=O)Nc2cc([R3])c([R])cc23)cc1</smiles>

Figure 1. Bioactive compounds incorporating spirooxindole, and thiochromane skeletons.

Barakat et al. reported the synthesis and biological activities of several spirooxindoles they exhibited interesting pharmacological activities as MDM2-p53 protein-protein interaction inhibitors, phosphodiesterase 1 , and as selective cyclooxygenase COX-1 with TNF- $\alpha$ and IL- 6 inhibitors. These spirooxindoles were reported to have potential hypoglycemic activity with inhibitory activities against $\alpha$-amylase and $\alpha$-glucosidase, and other pharmacological targets [26-34].

Another interesting motif is thiochromane and its analogues. Thiochromanone, thiochromane, and thiochromene derivatives are known to exhibit anticancer [35], antiviral [36], non-steroidal estrogen downregulation [36], human steroid sulfatase inhibition [37-40], $\alpha$-adrenergic antagonism [41], and has antiparasitic [42], and antifungal [43] properties.

There are many reports on different approaches in the literature on the construction of spirooxindole systems [44,45]. For example, Mannich reactions and related transformations were successfully employed in the construction of naturally occurring spirooxindole alkaloid, $( \pm)$-elacomine [46]. An oxidative rearrangement approach of tetrahydro- $\beta$-carbolines and related core structures [47], an intra-molecular Heck reaction and similar transformations approach were reported by L. Overman and M. Rosen for the total synthesis 
of spiro-trypro-statins B [48]. Transition metal-catalyzed synthesis of the spirooxindole scaffold [49] and 1,3-dipolar cycloaddition reactions are regarded as useful approaches for the construction of the spirooxindole scaffold [50]. However, successful approaches for the synthesis of thio-chromenyl/spirooxindole systems are still limited, although replacement of the oxygen atom by sulfur could be a rational strategy for improving pharmacological activity in drug discovery [51-53]. The design and synthesis of new compounds as potent and safe anti-cancer agents with low side effects is still a challenge.

Based on literature reports which highlight the biological importance of thiochromene sub-structure and spirooxindole/pyrrolidine scaffolds, our aim was to synthesize a new hybrids comprising three pharmacophores, spirooxindole/pyrrolidine/thiochromene employing three components 1,3-dipolar cycloaddition reaction. This protocol is based on multiple bond formations [54] and hence were able to generate compounds with structural complexity for possible use in agrochemical, drug discovery, and pharmaceutical industries.

\section{Materials and Methods}

\subsection{General}

“Thiochroman-3-one, acetophenone derivatives, substituted isatins and L-proline were purchased from Aldrich or TCI, and used as received. All solvents were used as received when experiments were conducted in air. Flash chromatography was performed on 100-200 mesh silica gel. The ${ }^{1} \mathrm{H}$ - and ${ }^{13} \mathrm{C}-\mathrm{NMR}$ spectra of the synthesized compound were recorded on a JEOL 400-MHz spectrometer (JEOL, Ltd., Tokyo, Japan) at ambient temperature. The solvents used were DMSO- $d_{6}$, and $\mathrm{CDCl}_{3}$; the chemical shifts $(\delta)$ were given in ppm. Single-crystal X-ray data of compound $7 \mathbf{m}$ were collected on a Rigaku Oxford Diffraction Supernova diffractometer at $120 \mathrm{~K}$. Melting points were determined using Mel-Temp apparatus and are uncorrected. Thin Layer Chromatography (TLC) was conducted on silica gel (Kiesel gel G, E.Merck) and spots were detected under UV light at $254 \mathrm{~nm}$. FT-IR spectra were measured on a Perkin Elmer, Spectrum 100 FT-IR spectrometer (FT-IR, Perkin Elmer, USA). Mass spectra were recorded on a Shimadzu GCMS-QP 1000 EX mass spectrometer at $70 \mathrm{eV}^{\prime \prime}$.

\subsection{Synthesis of 4-Chloro-2H-thiochromene-3-carbaldehyde (2)}

Phosphorus oxychloride $(32 \mathrm{~mL}, 350 \mathrm{mmol})$ was added dropwise at a steady rate to a cold solution $\left(0-5{ }^{\circ} \mathrm{C}\right)$ of $\mathrm{N}, \mathrm{N}$-dimethylformamide $(11.5 \mathrm{~mL}, 150 \mathrm{mmol})$. After $30 \mathrm{~min}$, thiochroman-3-one $(8.2 \mathrm{~g}, 50 \mathrm{mmol})$ was added. The resulting mixture was allowed to heat to $100{ }^{\circ} \mathrm{C}$ for $1.5 \mathrm{~h}$. The reaction mixture was poured slowly into a cold water ( $\left.300 \mathrm{~mL}\right)$, and the precipitated product was filtered and dried in vacuum at $40^{\circ} \mathrm{C}$ for $24 \mathrm{~h}$ to obtain a light yellow solid compound 4-chloro-2H-thiochromene-3-carbaldehyde (2) [49].

Yield (8.5 g, yield: $81 \%$ ); m.p. $139-141{ }^{\circ} \mathrm{C} ;{ }^{1} \mathrm{H}-\mathrm{NMR}\left(400 \mathrm{MHz}, \mathrm{DMSO}-d_{6}\right): \delta$ $(\mathrm{ppm})=10.22(\mathrm{~d}, J=2.2 \mathrm{~Hz}, 1 \mathrm{H}, \mathrm{CHO}), 7.96-7.88(\mathrm{~m}, 1 \mathrm{H}, \mathrm{Ar}-\mathrm{H}), 7.51-7.40(\mathrm{~m}, 2 \mathrm{H}, \mathrm{Ar}-\mathrm{H})$, $7.37(\mathrm{dd}, J=8.5,6.3 \mathrm{~Hz}, 1 \mathrm{H}, \mathrm{Ar}-\mathrm{H}), 3.72\left(\mathrm{~d}, J=2.3 \mathrm{~Hz}, 2 \mathrm{H}, \mathrm{SCH}_{2}\right) ;{ }^{13} \mathrm{C}-\mathrm{NMR}(101 \mathrm{MHz}$ DMSO- $\left.d_{6}\right): \delta(\mathrm{ppm})=189.0-(\mathrm{CHO}), 145.0,137.0-, 132.0-, 131.0-, 128.6-, 127.7-, 127.0-, 126.5-$, 22.8- $\left(\mathrm{SCH}_{2}\right)$; [Anal. Calcd. for $\mathrm{C}_{10} \mathrm{H}_{7} \mathrm{ClOS}: \mathrm{C}, 57.01 ; \mathrm{H}, 3.35$; Found: $\mathrm{C}, 57.13 ; \mathrm{H}, 3.24$ ]; $\mathrm{LC} / \mathrm{MS}$ (ESI, $\mathrm{m} / \mathrm{z}$ ): found $211.22\left[\mathrm{M}+\mathrm{H}^{+}\right]$. All the analytical data were in agreement with the reported literature [37].

\subsection{Synthesis of Thiochromene Chalcones (4a-e)}

General procedure (GP1): 4-Chloro-2H-thiochromene-3-carbaldehyde (2) (1.05 g, $5.0 \mathrm{mmol}$ ) and acetophenone derivatives (3a-e) $(5.0 \mathrm{mmol})$ were dissolved fully (by heating if necessary) in $30 \mathrm{~mL}$ ethanol and then $\mathrm{NaOH}$ solution in water $(30 \mathrm{~mL}, 20 \mathrm{mmol})$ was added. The reaction mixture was left for stirring overnight. Light yellow solid precipitates emerged which were filtered and washed with water and ethanol to afford pure chalcone (4a-e).

(E)-3-(4-Chloro-2H-thiochromen-3-yl)-1-(4-chlorophenyl)prop-2-en-1-one (4a) 
Following GP1, 4-chloro-2H-thiochromene-3-carbaldehyde (2) (1.05 g, $5.0 \mathrm{mmol})$ reacted with 4-chloroacetophenone $(3 \mathrm{~b})(0.77 \mathrm{~g}, 5.0 \mathrm{mmol})$ to produce the chalcone $(4 \mathbf{b})$ (yield $1.51 \mathrm{~g}, 87 \%)$; m.p. $118-119 ;{ }^{1} \mathrm{H}-\mathrm{NMR}\left(400 \mathrm{MHz}, \mathrm{CDCl}_{3}\right): \delta(\mathrm{ppm})=8.24(\mathrm{~d}, J=15.4 \mathrm{~Hz}, 1 \mathrm{H}$, $\mathrm{CH}=\mathrm{CH}), 7.96-7.89(\mathrm{~m}, 2 \mathrm{H}, \mathrm{Ar}-\mathrm{H}), 7.86-7.81(\mathrm{~m}, 1 \mathrm{H}, \mathrm{Ar}-\mathbf{H}), 7.47(\mathrm{~d}, J=8.7 \mathrm{~Hz}, 2 \mathrm{H}, \mathrm{Ar}-\mathrm{H})$, 7.36-7.31 (m, 1H, Ar-H), 7.25-7.19 (m, 2H, Ar-H), $7.10(\mathrm{~d}, J=15.4 \mathrm{~Hz}, 1 \mathrm{H}, \mathrm{CH}=\mathrm{CH}), 3.72$ $\left.(\mathrm{s}, 2 \mathrm{H}, \mathrm{SCH})_{2}\right) ;{ }^{13} \mathrm{C}\left\{{ }^{1} \mathrm{H}\right\}-\mathrm{NMR}\left(126 \mathrm{MHz} \mathrm{CDCl}_{3}\right): \delta(\mathrm{ppm})=189.2(\mathrm{CO}), 141.0-, 139.5-, 138.0-$, 136.4-, 135.1-, 132.7, 130.0-, 130.0-, 129.1-, 128.9-, 127.4, 126.3, 126.2-, 124.1, $26.9\left(\mathrm{SCH}_{2}\right)$; IR $\left(\mathrm{KBr}, \mathrm{cm}^{-1}\right) v_{\max }=3087,2363,2340,1654,1592,1577,1568,1540,1488,1456,1431,1412$, 1401, 1325, 1308, 1294, 1261, 1245, 1212, 1180, 1090, 1029, 1014, 964, 911, 845, 822, 759, 752, 720, 649, 608; [Anal. Calcd. for $\mathrm{C}_{8} \mathrm{H}_{12} \mathrm{Cl}_{2} \mathrm{OS}$ : C, 62.26; H, 3.48; Found: C, 62.33; H, 3.39]; LC/MS (ESI, $m / z)$ : found $347.21\left[\mathrm{M}+\mathrm{H}^{+}\right]$.

(E)-3-(4-Chloro-2H-thiochromen-3-yl)-1-(4-fluorophenyl)prop-2-en-1-one (4b)

Following GP1, 4-chloro-2H-thiochromene-3-carbaldehyde (2) (1.05 g, $5.0 \mathrm{mmol}) \mathrm{re}$ acted with 4-fluoroacetophenone (3c) $(0.69 \mathrm{~g}, 5.0 \mathrm{mmol})$ to produce the chalcone (4c) (yield $1.47 \mathrm{~g}, 89 \%)$; m.p. 104-105; ${ }^{1} \mathrm{H}-\mathrm{NMR}\left(400 \mathrm{MHz}, \mathrm{CDCl}_{3}\right): \delta(\mathrm{ppm})=8.24(\mathrm{~d}, \mathrm{~J}=15.8 \mathrm{~Hz}$, $1 \mathrm{H}, \mathrm{CH}=\mathrm{CH}), 8.06-7.99(\mathrm{~m}, 2 \mathrm{H}, \mathrm{Ar}-\mathbf{H}), 7.86-7.81(\mathrm{~m}, 1 \mathrm{H}, \mathrm{Ar}-\mathbf{H}), 7.36-7.31$ (m, 1H, Ar-H), 7.25-7.21 (m, 2H, Ar-H), $7.18(\mathrm{t}, J=8.6 \mathrm{~Hz}, 2 \mathrm{H}, \mathrm{Ar}-\mathrm{H}), 7.13(\mathrm{~d}, J=15.8 \mathrm{~Hz}, 1 \mathrm{H}, \mathrm{CH}=\mathrm{CH})$, $3.73\left(\mathrm{~s}, 2 \mathrm{H}, \mathrm{SCH}_{2}\right) ;{ }^{13} \mathrm{C}-\mathrm{NMR}\left(126 \mathrm{MHz} \mathrm{CDCl}_{3}\right): \delta(\mathrm{ppm})=188.9(\mathrm{CO}), 166.9 \& 164.0(\mathrm{~d}$, $\left.J_{\mathrm{C} 1-\mathrm{F}}=238.96 \mathrm{~Hz}\right), 140.7,137.7,135.1,134.5,132.7,131.3 \& 131.2\left(\mathrm{~d}, J_{\mathrm{C} 3-\mathrm{F}}=9.32 \mathrm{~Hz}\right), 123.0$, $129.0,127.4,126.3,124.2,116.0 \& 116.0\left(\mathrm{~d}, J_{\mathrm{C} 2-\mathrm{F}}=21.67 \mathrm{~Hz}\right), 26.9\left(\mathrm{SCH}_{2}\right) ; \mathrm{IR}\left(\mathrm{KBr}, \mathrm{cm}^{-1}\right)$ $v_{\max }=3059,2360,2336,1652,1596,1572,1564,1537,1502,1432,1415,1404,1223,1312$, 1296, 1262, 1223, 1213, 1152, 1029, 1009, 969, 947, 909, 861, 852, 827, 805, 762, 603; [Anal. Calcd. for $\mathrm{C}_{8} \mathrm{H}_{12}$ ClFOS: C, 65.35; H, 3.66; Found: C, 65.47; H, 3.59]; LC/MS (ESI, $m / z$ ): found $331.14\left[\mathrm{M}+\mathrm{H}^{+}\right]$.

(E)-3-(4-Chloro-2H-thiochromen-3-yl)-1-(4-nitrophenyl)prop-2-en-1-one (4c)

Following GP1, 4-chloro-2H-thiochromene-3-carbaldehyde (2) (1.05 g, $5.0 \mathrm{mmol}) \mathrm{re}-$ acted with 4-nitroacetophenone $(3 \mathbf{f})(0.83 \mathrm{~g}, 5.0 \mathrm{mmol})$ to produce the chalcone (4f) (yield 1.48 g, 83\%); m.p. $180-181 ;{ }^{1} \mathrm{H}-\mathrm{NMR}\left(400 \mathrm{MHz}, \mathrm{CDCl}_{3}\right): \delta(\mathrm{ppm})=8.35(\mathrm{~d}, J=8.7 \mathrm{~Hz}, 2 \mathrm{H}$, Ar-H), $8.28(\mathrm{~d}, J=16.1 \mathrm{~Hz}, 1 \mathrm{H}, \mathrm{CH}=\mathrm{CH}), 8.15-8.08(\mathrm{~m}, 2 \mathrm{H}, \mathrm{Ar}-\mathbf{H}), 7.88-7.81(\mathrm{~m}, 1 \mathrm{H}, \mathrm{Ar}-\mathrm{H})$, 7.37-7.33 (m, 1H, Ar-H), 7.28-7.24 (m, 3H, Ar-H), 7.10 (d, J = 15.5 Hz, 1H, CH = CH), ), 3.74 $\left(\mathrm{s}, 2 \mathrm{H}, \mathrm{SCH}_{2}\right) ;{ }^{13} \mathrm{C}-\mathrm{NMR}\left(101 \mathrm{MHz}, \mathrm{CDCl}_{3}\right): \delta(\mathrm{ppm})=189.1(\mathrm{CO}), 150.3,143.0,142.2,139.0$, $135.3,132.6,130.2,129.6,129.1,127.4,126.4,126.0,124.0,123.8,26.8\left(\mathrm{SCH}_{2}\right)$; IR $\left(\mathrm{KBr}, \mathrm{cm}^{-1}\right)$ $v_{\max }=3107,2360,1664,1602,1563,1539,1519,1433,1407,1344,1323,1308,1264,1243$, 1209, 1032, 1011, 965, 912, 899, 835, 759, 704; [Anal. Calcd. for $\mathrm{C}_{8} \mathrm{H}_{12} \mathrm{ClNO}_{3} \mathrm{~S}$ : C, 60.42; $\mathrm{H}$, 3.38; N, 3.91; Found: C, 60.31; H, 3.27; N, 3.84]; LC/MS (ESI, $m / z)$ : found $358.17\left[\mathrm{M}+\mathrm{H}^{+}\right]$.

\section{(E)-3-(4-Chloro-2H-thiochromen-3-yl)-1-(4-bromophenyl)prop-2-en-1-one (4d)}

Following GP1, 4-chloro-2H-thiochromene-3-carbaldehyde (2) (1.05 g, $5.0 \mathrm{mmol}) \mathrm{re}$ acted with 4-bromoacetophenone (3d) $(1.0 \mathrm{~g}, 5.0 \mathrm{mmol})$ to produce the chalcone (4d) (yield $1.66 \mathrm{~g}, 85 \%)$; m.p. $141-142 ;{ }^{1} \mathrm{H}-\mathrm{NMR}\left(400 \mathrm{MHz}, \mathrm{CDCl}_{3}\right): \delta(\mathrm{ppm})=8.24(\mathrm{~d}, J=15.5 \mathrm{~Hz}$, $1 \mathrm{H}, \mathrm{CH}=\mathrm{CH}), 7.88-7.80(\mathrm{~m}, 3 \mathrm{H}, \mathrm{Ar}-\mathrm{H}), 7.64(\mathrm{~d}, J=8.1 \mathrm{~Hz}, 2 \mathrm{H}, \mathrm{Ar}-\mathrm{H}), 7.33(\mathrm{~d}, J=4.4 \mathrm{~Hz}$, 1H, Ar-H), 7.24 (dd, J = 8.8, 4.3 Hz, 2H, Ar-H), 7.09 (d, J = 16.0 Hz, 1H, CH = CH), 3.72 (s, $\left.2 \mathrm{H}, \mathrm{SCH}_{2}\right) ;{ }^{13} \mathrm{C}-\mathrm{NMR}\left(101 \mathrm{MHz}, \mathrm{CDCl}_{3}\right): \delta(\mathrm{ppm})=189.4(\mathrm{CO}), 141.0,138.0,136.9,135.2$, $132.7,132.1,130.2,130.0,129.0,128.2,127.4,126.3,126.2,124.0,26.9\left(\mathrm{SCH}_{2}\right)$; IR $\left(\mathrm{KBr}, \mathrm{cm}^{-1}\right)$ $v_{\max }=3083,2372,1653,1584,1576,1539,1484,1430,1324,1308,1294,1244,1212,1181$, 1068, 1028, 1008, 964, 945, 911, 844, 819, 758, 752, 718, 608; [Anal. Calcd. for $\mathrm{C}_{18} \mathrm{H}_{12} \mathrm{BrClOS}$ : C, 55.19; H, 3.09; Found: C, 54.97; H, 3.02]; LC/MS (ESI, $m / z)$ : found $391.19\left[\mathrm{M}+\mathrm{H}^{+}\right]$.

(E)-3-(4-Chloro-2H-thiochromen-3-yl)-1-(4-(trifluoromethyl)phenyl)-prop-2-en-1-one (4e)

Following GP1, 4-chloro-2H-thiochromene-3-carbaldehyde (2) (1.05 g, $5.0 \mathrm{mmol}$ ) reacted with 4-(trifluoromethyl)acetophenone (3e) $(0.94 \mathrm{~g}, 5.0 \mathrm{mmol})$ to produce the chalcone (4e) (yield 1.52 g, 80\%); m.p. $149-150 ;{ }^{1} \mathrm{H}-\mathrm{NMR}\left(400 \mathrm{MHz}, \mathrm{CDCl}_{3}\right): \delta(\mathrm{ppm})=8.27(\mathrm{~d}$, $J=16.0 \mathrm{~Hz}, 1 \mathrm{H}, \mathrm{CH}=\mathrm{CH}), 8.07(\mathrm{~d}, J=8.1 \mathrm{~Hz}, 2 \mathrm{H}, \mathrm{Ar}-\mathbf{H}), 7.86-7.81(\mathrm{~m}, 1 \mathrm{H}, \mathrm{Ar}-\mathrm{H}), 7.77(\mathrm{~d}$, $J=8.1 \mathrm{~Hz}, 2 \mathrm{H}, \mathrm{Ar}-\mathbf{H}), 7.37-7.32$ (m, 1H, Ar-H), 7.28-7.21 (m, 2H, Ar-H), 7.11 (d, J = 16.0 Hz, 
$1 \mathrm{H}, \mathrm{CH}=\mathrm{CH}), 3.74\left(\mathrm{~s}, 2 \mathrm{H}, \mathrm{SCH}_{2}\right) ;{ }^{13} \mathrm{C}-\mathrm{NMR}\left(101 \mathrm{MHz}, \mathrm{CDCl}_{3}\right): \delta(\mathrm{ppm})=189.6(\mathrm{CO})$, 141.6, 141.0, 138.4, 135.2, 132.6, 130.1, 129.0, 129.0, 127.4, 126.3, 126.1, 125.9, 125.9, 124.0, $26.8\left(\mathrm{SCH}_{2}\right) ; \mathrm{IR}\left(\mathrm{KBr}, \mathrm{cm}^{-1}\right) v_{\max }=3055,1656,1590,1579,1569,1543,1433,1409,1319,1306$, 1266, 1247, 1210, 1188, 1175, 1123, 1111, 1065, 965, 943, 912, 829, 757, 718, 681; [Anal. Calcd. for $\mathrm{C}_{19} \mathrm{H}_{1} 2 \mathrm{ClF}_{3} \mathrm{OS}$ : C, 59.93; H, 3.18; Found: $\left.\mathrm{C}, 60.14 ; \mathrm{H}, 3.13\right]$; LC/MS (ESI, $\left.m / z\right)$ : found $381.13\left[\mathrm{M}+\mathrm{H}^{+}\right]$.

\subsection{Synthesis of Spirooxindole/Pyrrolidine/Thiochromene (7a-m)}

Substituted (E)-3-(4-chloro-2H-thiochromen-3-yl)-1-phenylprop-2-en-1-one (4a-e) $(0.5 \mathrm{mmol})$, isatin derivatives (6a-e) $(0.5 \mathrm{mmol})$, and L-proline $5(57.5 \mathrm{mg}, 0.5 \mathrm{mmol})$ were dissolved in methanol $(20 \mathrm{~mL})$ and the reaction mixture was refluxed for 3-6 h. Finally, the products were isolated by flash column chromatography using 100-200 mesh silica gel and $\mathrm{MeOH} / \mathrm{CH}_{2} \mathrm{Cl}_{2}$ (2:98) as an eluent to afford pure 4-chloro- $2 \mathrm{H}$-thiochromen spirooxindoles (7a-m).

$1^{\prime}$-(4-Chloro-2H-thiochromen-3-yl)-2'-(4-chlorobenzoyl)-1' $2^{\prime}, 5^{\prime}, 6^{\prime}, 7^{\prime}, 7 \mathrm{a}^{\prime}$-hexahydro-spiro[indoline-3,3'-pyrrolizin]-2-one (7a)

(E)-3-(4-Chloro-2H-thiochromen-3-yl)-1-(4-chlorophenyl)prop-2-en-1-one (4a) (174 mg, $0.5 \mathrm{mmol})$, L-proline (5) $(57.5 \mathrm{mg}, 0.5 \mathrm{mmol})$ and isatin $(6 \mathbf{6 a})(74 \mathrm{mg}, 0.5 \mathrm{mmol})$ were reacted according to GP2 for 3-6 h and yielded white solid thio-chromen spirooxindole (7a) (149 mg, 86\%); m.p.75-76 ${ }^{\circ} \mathrm{C} ;{ }^{1} \mathrm{H}-\mathrm{NMR}\left(500 \mathrm{MHz}, \mathrm{CDCl}_{3}\right): \delta(\mathrm{ppm})=8.22(\mathrm{~s}, 1 \mathrm{H}, \mathrm{NH}), 7.73(\mathrm{~d}$, $J=7.7 \mathrm{~Hz}, 1 \mathrm{H}, \mathrm{Ar}-\mathrm{H}), 7.38(\mathrm{dd}, J=8.6,1.8 \mathrm{~Hz}, 2 \mathrm{H}, \mathrm{Ar}-\mathrm{H}), 7.26-7.23(\mathrm{~m}, 2 \mathrm{H}, \mathrm{Ar}-\mathrm{H}), 7.19-7.14$ $(\mathrm{m}, 3 \mathrm{H}, \mathrm{Ar}-\mathrm{H}), 7.12(\mathrm{t}, J=7.4 \mathrm{~Hz}, 2 \mathrm{H}, \mathrm{Ar}-\mathrm{H}), 6.99(\mathrm{t}, J=7.4 \mathrm{~Hz}, 1 \mathrm{H}, \mathrm{Ar}-\mathrm{H}), 6.62(\mathrm{~d}, J=8.0 \mathrm{~Hz}$, $1 \mathrm{H}, \mathrm{Ar}-\mathrm{H}), 4.72(\mathrm{~d}, J=11.1 \mathrm{~Hz}, 1 \mathrm{H}, \mathrm{COCH}), 4.64(\mathrm{t}, J=10.0 \mathrm{~Hz}, 1 \mathrm{H}, \mathrm{NCHCH}), 4.15(\mathrm{td}$, $J=9.0,8.1,3.4 \mathrm{~Hz}, 1 \mathrm{H}, \mathrm{NCH}), 3.61\left(\mathrm{~d}, J=14.7 \mathrm{~Hz}, 1 \mathrm{H}, \mathrm{SCH}_{2(\mathrm{a})}\right), 3.53(\mathrm{~d}, J=14.7 \mathrm{~Hz}$, $\left.1 \mathrm{H}, \mathrm{SCH}_{2(\mathrm{~b})}\right), 2.81-2.72\left(\mathrm{~m}, 1 \mathrm{H}, \mathrm{NCH}_{2(\mathrm{a})}\right), 2.67-2.60\left(\mathrm{~m}, 1 \mathrm{H}, \mathrm{NCH}_{2(\mathrm{a})}\right), 2.14-2.08(\mathrm{~m}, 1 \mathrm{H}$, $\left.\mathrm{CH}_{2}\right), 2.01-1.92\left(\mathrm{~m}, 2 \mathrm{H}, \mathrm{CH}_{2}\right), 1.92-1.85\left(\mathrm{~m}, 1 \mathrm{H}, \mathrm{CH}_{2}\right) ;{ }^{13} \mathrm{C} \mathrm{NMR}\left(126 \mathrm{MHz}, \mathrm{CDCl}_{3}\right): \delta$ $(\mathrm{ppm})=195.6(\mathrm{CO}), 180.6-(\mathrm{CO}), 140.7-, 139.7,135.3-, 133.7,133.0-, 130.2-, 130.0,129.4,128.7$, $128.7,128.4,127.8,127.8,127.1,125.9,124.7,122.8,110.4,68.3,59.6,53.6,50.7,48.6,30.2,26.9$, $26.7\left(\mathrm{CH}_{2}\right)$; IR $\left(\mathrm{KBr}, \mathrm{cm}^{-1}\right) v_{\max }=3201,3060,2964,2873,1721,1681,1618,1588,1569,1486$, 1471, 1435, 1400, 1387, 1328, 1291, 1254, 1232, 1207, 1178, 1134, 1112, 1091, 1012, 942, 901, 843, 794, 755, 724, 614, 532; [Anal. Calcd. for $\mathrm{C}_{30} \mathrm{H}_{24} \mathrm{Cl}_{2} \mathrm{~N}_{2} \mathrm{O}_{2} \mathrm{~S}$ : C, 65.81; H, 4.42; N, 5.12; Found: C, 65.93; H, 4.52; N, 5.01]; LC/MS (ESI, $m / z$ ): found $547.16\left[\mathrm{M}+\mathrm{H}^{+}\right]$.

6-Chloro-1'-(4-chloro-2H-thiochromen-3-yl)-2'-(4-chlorobenzoyl)-1' $2^{\prime}, 5^{\prime}, 6^{\prime}, 7^{\prime}, 7 \mathrm{a}^{\prime}$-h-exahydrospiro[indoline-3,3'-pyrrolizin]-2-one $(7 \mathbf{b})$

(E)-3-(4-Chloro-2H-thiochromen-3-yl)-1-(4-chlorophenyl)prop-2-en-1-one (4a) (174 mg, $0.5 \mathrm{mmol})$, L-proline (5) (57.5 mg, $0.5 \mathrm{mmol})$ and 6-chloroisatin $(6 \mathbf{b})(91 \mathrm{mg}, 0.5 \mathrm{mmol})$ were reacted according to GP2 for 3-6 h and yielded white solid thio-chromen spirooxindole (7b) $(253 \mathrm{mg}, 87 \%)$; m.p. $110-111^{\circ} \mathrm{C} ;{ }^{1} \mathrm{H}-\mathrm{NMR}\left(400 \mathrm{MHz}, \mathrm{CDCl}_{3}\right): \delta(\mathrm{ppm})=9.53(\mathrm{~s}, 1 \mathrm{H}$, NH), $7.96(\mathrm{~d}, J=5.9 \mathrm{~Hz}, 1 \mathrm{H}, \mathrm{Ar}-\mathrm{H}), 7.69(\mathrm{~d}, J=7.3 \mathrm{~Hz}, 1 \mathrm{H}, \mathrm{Ar}-\mathrm{H}), 7.43(\mathrm{~d}, J=8.8 \mathrm{~Hz}, 2 \mathrm{H}$, Ar-H), $7.19(\mathrm{~d}, J=8.8 \mathrm{~Hz}, 2 \mathrm{H}, \mathrm{Ar}-\mathrm{H}), 7.13(\mathrm{t}, J=7.0 \mathrm{~Hz}, 3 \mathrm{H}, \mathrm{Ar}-\mathrm{H}), 6.92(\mathrm{~d}, J=8.1 \mathrm{~Hz}$, $1 \mathrm{H}, \mathrm{Ar}-\mathrm{H}), 6.69(\mathrm{~s}, 1 \mathrm{H}, \mathrm{Ar}-\mathrm{H}), 4.70(\mathrm{~d}, J=11.0 \mathrm{~Hz}, 1 \mathrm{H}, \mathrm{COCH}), 4.61(\mathrm{t}, J=10.6 \mathrm{~Hz}, 1 \mathrm{H}$, $\mathrm{NCHCH}), 4.18-4.12(\mathrm{~m}, 1 \mathrm{H}, \mathrm{NCH}), 3.60\left(\mathrm{~d}, J=15.4 \mathrm{~Hz}, 1 \mathrm{H}, \mathrm{SCH}_{2(\mathrm{a})}\right), 3.52(\mathrm{~d}, J=14.7 \mathrm{~Hz}$, $\left.1 \mathrm{H}, \mathrm{SCH}_{2(\mathrm{~b})}\right), 2.76-2.76-2.69\left(\mathrm{~m}, 1 \mathrm{H}, \mathrm{NCH}_{2(\mathrm{a})}\right), 2.66-2.57\left(\mathrm{~m}, 1 \mathrm{H}, \mathrm{NCH}_{2(\mathrm{~b})}\right), 2.15-2.01(\mathrm{~m}$, $\left.1 \mathrm{H}, \mathrm{CH}_{2}\right), 1.95-184\left(\mathrm{~m}, 3 \mathrm{H}, \mathrm{CH}_{2}\right) ;{ }^{13} \mathrm{C}-\mathrm{NMR}\left(101 \mathrm{MHz}, \mathrm{CDCl}_{3}\right): \delta(\mathrm{ppm})=195.4(\mathrm{CO})$, 180.2 (CO), 174.3, 162.8, 142.7, 139.8, 135.6, 135.0, 133.6, 132.7, 130.2, 129.3, 128.8, 128.3, 127.6, 126.9, 125.8, 122.8, 122.3, 111.2, 72.9, 67.9, 58.9, 50.7, 48.5, 31.5, 29.7, $26.4\left(\mathrm{SCH}_{2}\right)$; IR $\left(\mathrm{KBr}, \mathrm{cm}^{-1}\right) v_{\max }=3064,2972,1730,1614,1588,1486,1458,1437,1401,1234,1091,1074$, 1012, 943, 845, 757, 724, 668, 608, 530; [Anal. Calcd. for $\mathrm{C}_{30} \mathrm{H}_{23} \mathrm{Cl}_{3} \mathrm{~N}_{2} \mathrm{O}_{2} \mathrm{~S}: \mathrm{C}, 61.92 ; \mathrm{H}, 3.98$; $\mathrm{N}$, 4.81; Found: C, 61.84; H, 4.05; N, 4.93]; LC/MS (ESI, $m / z)$ : found $581.23\left[\mathrm{M}+\mathrm{H}^{+}\right]$.

$1^{\prime}$-(4-Chloro-2H-thiochromen-3-yl)-2'-(4-chlorobenzoyl)-5-fluoro-1' ${ }^{\prime} 2^{\prime}, 5^{\prime}, 6^{\prime}, 7^{\prime}, 7 \mathrm{a}^{\prime}$-hexahydrospiro[indoline-3,3'-pyrrolizin]-2-one (7c)

(E)-3-(4-Chloro-2H-thiochromen-3-yl)-1-(4-chlorophenyl)prop-2-en-1-one (4a) (174 mg, $0.5 \mathrm{mmol})$, L-proline (5) $(57.5 \mathrm{mg}, 0.5 \mathrm{mmol})$ and 5-fluoroisatin $(6 \mathrm{c})(83 \mathrm{mg}, 0.5 \mathrm{mmol})$ were 
reacted according to GP2 for 3-6 h and yielded white solid thio-chromen spirooxindole (7c) (229 mg, 81\%); m.p. 150-1151 ${ }^{\circ} \mathrm{C} ;{ }^{1} \mathrm{H}-\mathrm{NMR}\left(400 \mathrm{MHz}, \mathrm{CDCl}_{3}\right): \delta(\mathrm{ppm})=9.35(\mathrm{~s}, 1 \mathrm{H}), 7.69$ $(\mathrm{d}, J=7.5 \mathrm{~Hz}, 1 \mathrm{H}), 7.44(\mathrm{~d}, J=8.6 \mathrm{~Hz}, 2 \mathrm{H}), 7.22(\mathrm{~d}, J=7.3 \mathrm{~Hz}, 1 \mathrm{H}), 7.17(\mathrm{~d}, J=8.3 \mathrm{~Hz}, 2 \mathrm{H})$, $7.14-7.06(\mathrm{~m}, 2 \mathrm{H}), 6.98(\mathrm{dd}, J=8.0,2.7 \mathrm{~Hz}, 1 \mathrm{H}), 6.81(\mathrm{td}, J=8.6,2.7 \mathrm{~Hz}, 1 \mathrm{H}), 6.59(\mathrm{dd}, J=8.7$, $4.3 \mathrm{~Hz}, 1 \mathrm{H}), 4.72(\mathrm{~d}, J=11.0 \mathrm{~Hz}, 1 \mathrm{H}, \mathrm{COCH}), 4.60(\mathrm{t}, J=10.3 \mathrm{~Hz}, 1 \mathrm{H}, \mathrm{NCHCH}), 4.19-7.12$ (m, 1H, NCH), $3.60\left(\mathrm{~d}, J=14.6 \mathrm{~Hz}, 1 \mathrm{H}, \mathrm{SCH}_{2(\mathrm{a})}\right), 3.52\left(\mathrm{~d}, J=14.8 \mathrm{~Hz}, 1 \mathrm{H}, \mathrm{SCH}_{2(\mathrm{a})}\right), 2.79-2.73$ $\left(\mathrm{m}, 1 \mathrm{H}, \mathrm{SCH}_{2(\mathrm{a})}\right), 2.67-2.60\left(\mathrm{~m}, 1 \mathrm{H}, \mathrm{SCH}_{2(\mathrm{~b})}\right), 2.13-2.08\left(\mathrm{~m}, 1 \mathrm{H}, \mathrm{CH}_{2}\right), 1.99-1.83(\mathrm{~m}, 3 \mathrm{H}$, $\left.\mathrm{CH}_{2}\right) ;{ }^{13} \mathrm{C} \mathrm{NMR}\left(126 \mathrm{MHz}, \mathrm{CDCl}_{3}\right): \delta(\mathrm{ppm})=195.3(\mathrm{CO}), 159.8(\mathrm{CO}), 157.9,140.0,136.6$, 135.2, 133.7, 133.0, 130.4, 129.5, 130.0, 128.5, 128.3, 127.9, 127.1, 126.0, 116.7, 116.5, 115.8, 115.6, 111.0, 110.9, 68.3, 53.6, 50.8, 48.5, 29.8, 27.0, $26.7\left(\mathrm{SCH}_{2}\right) ; \mathrm{IR}\left(\mathrm{KBr}, \mathrm{cm}^{-1}\right) v_{\max }=3213$, 3061, 2962, 2860, 1724, 1707, 1683, 1652, 1588, 1569, 1486, 1461, 1436, 1400, 1303, 1283, $1249,1189,1113,994,900,852,820,763,752,721,687,660,628,593,535$; [Anal. Calcd. for $\mathrm{C}_{30} \mathrm{H}_{23} \mathrm{Cl}_{2} \mathrm{FN}_{2} \mathrm{O}_{2} \mathrm{~S}$ : C, 63.72; H, 4.10; N, 4.95; Found: C, 63.57; H, 4.21; N, 4.84]; LC/MS (ESI, $m / z$ ): found $565.21\left[\mathrm{M}+\mathrm{H}^{+}\right]$.

1'-(4-Chloro-2H-thiochromen-3-yl)-5-fluoro-2'-(4-fluorobenzoyl)-1' , 2', $5^{\prime}, 6^{\prime}, 7^{\prime}, 7 \mathrm{a}^{\prime}$-hexahydrospiro[indoline-3,3'-pyrrolizin]-2-one (7d)

(E)-3-(4-Chloro-2H-thiochromen-3-yl)-1-(4-fluorophenyl)prop-2-en-1-one (4b) (164 mg, $0.5 \mathrm{mmol})$, L-proline (5) (57.5 mg, $0.5 \mathrm{mmol})$ and 5-fluoroisatin (6c) $(83 \mathrm{mg}, 0.5 \mathrm{mmol})$ were reacted according to GP2 for 3-6 h and yielded white solid thio-chromen spirooxindole (7d) (209 mg, 76\%); m.p. 200-201 ${ }^{\circ} \mathrm{C} ;{ }^{1} \mathrm{H}-\mathrm{NMR}\left(500 \mathrm{MHz}, \mathrm{CDCl}_{3}\right): \delta(\mathrm{ppm})=8.45(\mathrm{~s}, 1 \mathrm{H}, \mathrm{NH})$, $7.73(\mathrm{dd}, J=7.9,1.5 \mathrm{~Hz}, 1 \mathrm{H}, \mathrm{Ar}-\mathrm{H}), 7.54(\mathrm{dd}, J=8.9,5.3 \mathrm{~Hz}, 2 \mathrm{H}, \mathrm{Ar}-\mathrm{H}), 7.27-7.23(\mathrm{~m}, 1 \mathrm{H}$, Ar-H), 7.19-7.15 (m, 1H, Ar-H), 7.13 (dd, J = 7.5, 1.6 Hz, 1H, Ar-H), 7.03 (dd, J = 8.1, $2.5 \mathrm{~Hz}$, 1H, Ar-H), 6.92-6.87 (m, 2H, Ar-H), 6.87-6.83 (m, 1H, Ar-H), 6.59 (dd, J = 8.5, 4.2 Hz, 1H, Ar-H), $4.74(\mathrm{~d}, J=10.8 \mathrm{~Hz}, 1 \mathrm{H}, \mathrm{COCH}), 4.60$ (dd, $J=11.2,9.7 \mathrm{~Hz}, 1 \mathrm{H}, \mathrm{NCHCH}), 4.15-4.11$ $(\mathrm{m}, 1 \mathrm{H}, \mathrm{NCH}), 3.58\left(\mathrm{~d}, J=14.5 \mathrm{~Hz}, 1 \mathrm{H}, \mathrm{SCH}_{2(\mathrm{a})}\right), 3.52$ (d, $\left.J=14.5 \mathrm{~Hz}, 1 \mathrm{H}, \mathrm{SCH}_{2(\mathrm{~b})}\right), 2.77-2.71$ $\left(\mathrm{m}, 1 \mathrm{H}, \mathrm{NCH}_{2(\mathrm{a})}\right), 2.68-2.61\left(\mathrm{~m}, 1 \mathrm{H}, \mathrm{NCH}_{2(\mathrm{~b})}\right), 2.09-2.15\left(\mathrm{~m}, 1 \mathrm{H}, \mathrm{CH}_{2}\right), 2.03-1.85(\mathrm{~m}, 3 \mathrm{H}$, $\left.\mathrm{CH}_{2}\right) ;{ }^{13} \mathrm{C}-\mathrm{NMR}\left(126 \mathrm{MHz}, \mathrm{CDCl}_{3}\right): \delta(\mathrm{ppm})=194.8(\mathrm{CO}), 181.00(\mathrm{CO}), 166.9 \& 164.8(\mathrm{~d}$, $J_{\mathrm{C} 1-\mathrm{F}}=256.54 \mathrm{~Hz}, \mathrm{Ph}$ ring), $159.9 \& 157.9\left(\mathrm{~d}, J_{\mathrm{C} 1-\mathrm{F}}=242.8 \mathrm{~Hz}\right.$, indole ring), 136.6, 133.6, $133.3 \& 133.3\left(\mathrm{~d}, J_{\mathrm{C} 4-\mathrm{F}}=3.96 \mathrm{~Hz}, \mathrm{Ph}\right.$ ring), 132.9, $130.8 \& 130.7$ (d, J $J_{\mathrm{C} 3-\mathrm{F}}=9.45 \mathrm{~Hz}, \mathrm{Ph}$ ring), $130.4,128.4,127.8,127.1,126.7 \& 126.6\left(\mathrm{~d}, J_{\mathrm{C} 6-\mathrm{F}}=7.43 \mathrm{~Hz}\right.$, indole ring), 126.0, 116.6 \& 116.4 $\left(\mathrm{d}, J_{\mathrm{C} 2-\mathrm{F}}=23.56 \mathrm{~Hz}\right.$, indole ring $), 115.8 \& 115.6\left(\mathrm{~d}, J_{\mathrm{C} 2-\mathrm{F}}=21.92 \mathrm{~Hz}, \mathrm{Ph}\right.$ ring $), 115.6,111 \&$ $110.8\left(\mathrm{~d}, J_{\mathrm{C} 5-\mathrm{F}}=7.81 \mathrm{~Hz}\right.$, indole ring), 68.3, 59.5, 50.8, 48.4, 30.2, 27.1, $26.7\left(\mathrm{SCH}_{2}\right)$; IR $(\mathrm{KBr}$, $\left.\mathrm{cm}^{-1}\right) v_{\max }=3179,3074,2968,2877,2862,1718,1688,1634,1596,1505,1487,1472,1459$, 1298, 1260, 1230, 1207, 1189, 1156, 1137, 1106, 1078, 952, 857, 822, 813, 759, 722, 686; [Anal. Calcd. for $\mathrm{C}_{30} \mathrm{H}_{23} \mathrm{ClF}_{2} \mathrm{~N}_{2} \mathrm{O}_{2} \mathrm{~S}$ : C, 65.63; H, 4.22; N, 5.10; Found: C, 65.72; H, 4.37; N, 4.97]; LC/MS (ESI, $m / z)$ : found $549.17\left[\mathrm{M}+\mathrm{H}^{+}\right]$.

6-Chloro-1'-(4-chloro-2H-thiochromen-3-yl)-2'-(4-fluorobenzoyl)-1', $2^{\prime}, 5^{\prime}, 6^{\prime}, 7^{\prime}, 7 a^{\prime}$-hexahydrospiro[indoline-3,3'-pyrrolizin]-2-one (7e)

(E)-3-(4-Chloro-2H-thiochromen-3-yl)-1-(4-fluorophenyl)prop-2-en-1-one (4b) (164 mg, $0.5 \mathrm{mmol})$, L-proline (5) (57.5 mg, $0.5 \mathrm{mmol})$ and 6-chloroisatin (6b) (91 mg, $0.5 \mathrm{mmol})$ were reacted according to GP2 for 3-6 h and yielded white solid thio-chromen spirooxindole (7e) $(232 \mathrm{mg}, 82 \%) ;$ m.p. $114-115{ }^{\circ} \mathrm{C} ;{ }^{1} \mathrm{H}-\mathrm{NMR}\left(500 \mathrm{MHz}, \mathrm{CDCl}_{3}\right): \delta(\mathrm{ppm})=\delta 8.35(\mathrm{~s}, 1 \mathrm{H}$, NH), $7.72(\mathrm{dd}, J=7.9,1.6 \mathrm{~Hz}, 1 \mathrm{H}, \mathrm{Ar}-\mathrm{H}), 7.53$ (ddd, $J=8.9,5.3,1.4 \mathrm{~Hz}, 2 \mathrm{H}, \mathrm{Ar}-\mathrm{H}), 7.25$ (q, $J=1.3 \mathrm{~Hz}, 1 \mathrm{H}, \mathrm{Ar}-\mathrm{H}), 7.20-7.11$ (m, 3H, Ar-H), 7.00-6.97 (m, 1H, Ar-H), 6.92 (td, J = 8.6, $1.4 \mathrm{~Hz}, 2 \mathrm{H}, \mathrm{Ar}-\mathrm{H}), 6.67$ (d, J = 1.8 Hz, 1H, Ar-H), 4.73 (d, J = $11.0 \mathrm{~Hz}, 1 \mathrm{H}, \mathrm{COCH}), 4.62(\mathrm{t}$, $J=10.5 \mathrm{~Hz}, 1 \mathrm{H}, \mathrm{NCHCH}), 4.22-4.10(\mathrm{~m}, 1 \mathrm{H}, \mathrm{NCH}), 3.60\left(\mathrm{~d}, J=16.0 \mathrm{~Hz}, 1 \mathrm{H}, \mathrm{SCH}_{2(\mathrm{a})}\right), 3.53(\mathrm{~d}$, $\left.J=14.0 \mathrm{~Hz}, 1 \mathrm{H}, \mathrm{SCH}_{2(\mathrm{~b})}\right), 2.81-2.72\left(\mathrm{~m}, 1 \mathrm{H}, \mathrm{NCH}_{2(\mathrm{a})}\right), 2.68-2.60\left(\mathrm{~m}, 1 \mathrm{H}, \mathrm{NCH}_{2(\mathrm{~b})}\right), 2.14-2.10$ $\left(\mathrm{m}, 1 \mathrm{H}, \mathrm{CH}_{2}\right), 2.00-1.85\left(\mathrm{~m}, 3 \mathrm{H}, \mathrm{CH}_{2}\right) ;{ }^{13} \mathrm{C}-\mathrm{NMR}\left(126 \mathrm{MHz}, \mathrm{CDCl}_{3}\right): \delta(\mathrm{ppm})=194.9(\mathrm{CO})$, $180.4(\mathrm{CO}), 167.0 \& 165.0\left(\mathrm{~d}, J_{\mathrm{C} 1-\mathrm{F}}=256.54 \mathrm{~Hz}\right), 141.9,135.8,133.7,133.2,132.9,130.8$ \& $130.7\left(\mathrm{~d}, J_{\mathrm{C} 3-\mathrm{F}}=9.45 \mathrm{~Hz}\right), 130.4,128.9,128.5,128.3,127.8,127.1,125.9,122.8,115.9 \& 115.8$ $\left(\mathrm{d}, J_{\mathrm{C} 2-\mathrm{F}}=21.80 \mathrm{~Hz}\right), 111.0,73.0,68.2,59.1,50.9,48.6,30.0,26.8,26.6\left(\mathrm{SCH}_{2}\right) ; \mathrm{IR}\left(\mathrm{KBr}, \mathrm{cm}^{-1}\right)$ $v_{\max }=3231,3066,2964,2868,1727,1681,1613,1597,1506,1485,1459,1411,1324,1235,1207$, 1157, 1133, 1074, 944, 921, 848, 813, 757, 625, 600; [Anal. Calcd. for $\mathrm{C}_{30} \mathrm{H}_{23} \mathrm{Cl}_{2} \mathrm{FN}_{2} \mathrm{O}_{2} \mathrm{~S}$ : C, 
63.72; H, 4.10; N, 4.95; Found: C, 63.64; H, 4.28; N, 5.09]; LC/MS (ESI, $m / z)$ : found 565.19 $\left[\mathrm{M}+\mathrm{H}^{+}\right]$.

1'-(4-Chloro-2H-thiochromen-3-yl)-5-fluoro-2'-(4-nitrobenzoyl)-1' $2^{\prime} 2^{\prime}, 5^{\prime}, 6^{\prime}, 7^{\prime}, 7 a^{\prime}$-hexahydrospiro[indoline-3, $3^{\prime}$-pyrrolizin]-2-one $(\mathbf{7 f})$

(E)-3-(4-Chloro-2H-thiochromen-3-yl)-1-(4-nitrophenyl)prop-2-en-1-one (4c) (179 mg, $0.5 \mathrm{mmol})$, L-proline (5) (57.5 mg, $0.5 \mathrm{mmol})$ and 5-fluoroisatin $(6 \mathrm{c})(83 \mathrm{mg}, 0.5 \mathrm{mmol})$ were reacted according to GP2 for 3-6 h and yielded yellow colored solid thio-chromen spirooxindole (7f) (213 mg, 74\%); m.p. $165-166{ }^{\circ} \mathrm{C} ;{ }^{1} \mathrm{H}-\mathrm{NMR}\left(500 \mathrm{MHz}, \mathrm{CDCl}_{3}\right): \delta$ (ppm) = $8.34(\mathrm{~s}$, $1 \mathrm{H}, \mathrm{NH}), 8.15-8.04(\mathrm{~m}, 2 \mathrm{H}, \mathrm{Ar}-\mathrm{H}), 7.74(\mathrm{dd}, J=8.2,1.9 \mathrm{~Hz}, 1 \mathrm{H}, \mathrm{Ar}-\mathrm{H}), 7.64(\mathrm{~d}, J=8.5 \mathrm{~Hz}, 2 \mathrm{H}$, Ar-H), 7.30-7.26 (m, 1H, Ar-H), 7.22-7.10 (m, 2H, Ar-H), 6.99 (dd, J = 8.0, 2.7 Hz, 1H, Ar-H), $6.88(\mathrm{td}, J=8.8,2.3 \mathrm{~Hz}, 1 \mathrm{H}, \mathrm{Ar}-\mathrm{H}), 6.61(\mathrm{dd}, J=8.6,4.1 \mathrm{~Hz}, 1 \mathrm{H}, \mathrm{Ar}-\mathrm{H}), 4.79$ (d, $J=11.0 \mathrm{~Hz}$, $1 \mathrm{H}, \mathrm{COCH}), 4.62(\mathrm{t}, J=10.3 \mathrm{~Hz}, 1 \mathrm{H}, \mathrm{NCHCH}), 4.30-4.16(\mathrm{~s}, 1 \mathrm{H}, \mathrm{NCH}), 3.64$ (d, J = 14.7 Hz, $\left.1 \mathrm{H}, \mathrm{SCH}_{2(\mathrm{a})}\right), 3.59$ (d, J = 14.6 Hz, 1H, SCH $(\mathrm{b})$ ), 2.93-2.78 (m, 1H, NCH $\left.\mathrm{Na}_{2}\right), 2.77-2.63(\mathrm{~m}$, $\left.1 \mathrm{H}, \mathrm{NCH}_{2(\mathrm{~b})}\right), 2.18-2.14\left(\mathrm{~m}, 1 \mathrm{H}, \mathrm{CH}_{2}\right), 2.04-1.93\left(\mathrm{~m}, 3 \mathrm{H}, \mathrm{CH}_{2}\right) ;{ }^{13} \mathrm{C}-\mathrm{NMR}\left(126 \mathrm{MHz}, \mathrm{CDCl}_{3}\right)$ : $\delta(\mathrm{ppm})=195.6(\mathrm{CO}), 180.6(\mathrm{CO}), 159.9 \& 157.9\left(\mathrm{~d}, J_{\mathrm{C} 1-\mathrm{F}}=243.56 \mathrm{~Hz}\right), 150.3,141.4,136.6$, $133.6,132.9,130.6,129.0,128.6,128.0,127.9,127.1,126.3 \& 126.3\left(\mathrm{~d}, J_{\mathrm{C} 3-\mathrm{F}}=6.93 \mathrm{~Hz}\right), 126.0$, $123.7,117.0 \& 116.7\left(\mathrm{~d}, J_{\mathrm{C} 2-\mathrm{F}}=25.07 \mathrm{~Hz}\right), 115.7 \& 115.5\left(\mathrm{~d}, J_{\mathrm{C} 6-\mathrm{F}}=23.56 \mathrm{~Hz}\right), 111.1 \& 111.1$ $\left(\mathrm{d}, J_{\mathrm{C} 5-\mathrm{F}}=8.06 \mathrm{~Hz}\right), 68.2,60.6,50.7,48.3,30.2,27.1,26.7\left(\mathrm{SCH}_{2}\right) ; \mathrm{IR}\left(\mathrm{KBr}, \mathrm{cm}^{-1}\right) v_{\max }=3392$, 3086, 2970, 2893, 2868, 2845, 1740, 1713, 1690, 1326, 1603, 1521, 1485, 1460, 1435, 1347, 1320, 1258, 1180, 1116, 1024, 1011, 988, 945, 900, 868, 856, 760, 720, 709, 683, 630, 594, 557; [Anal. Calcd. for $\mathrm{C}_{30} \mathrm{H}_{23} \mathrm{ClFN}_{3} \mathrm{O}_{4} \mathrm{~S}$ : C, 62.55; H, 4.02; N, 7.29; Found: C, 62.75; H, 4.17; N, 7.13]; LC/MS (ESI, $m / z)$ : found $576.13\left[\mathrm{M}+\mathrm{H}^{+}\right]$.

6-Chloro-1'-(4-chloro-2H-thiochromen-3-yl)-2'-(4-nitrobenzoyl)-1', $2^{\prime}, 5^{\prime}, 6^{\prime}, 7^{\prime}, 7 \mathrm{a}^{\prime}$-hexahydrospiro[indoline-3, $3^{\prime}$-pyrrolizin]-2-one $(7 \mathbf{g})$

(E)-3-(4-Chloro-2H-thiochromen-3-yl)-1-(4-nitrophenyl)prop-2-en-1-one (4c) (179 mg, $0.5 \mathrm{mmol})$, L-proline (5) (57.5 mg, $0.5 \mathrm{mmol}$ ) and 6-chloroisatin (6d) (91 mg, $0.5 \mathrm{mmol}$ ) were reacted according to GP2 for 3-6 h and yielded yellow colored solid thio-chromen spirooxindole (7g) (234 mg, 79\%); m.p. $143-144{ }^{\circ} \mathrm{C} ;{ }^{1} \mathrm{H}-\mathrm{NMR}\left(500 \mathrm{MHz}, \mathrm{CDCl}_{3}\right): \delta(\mathrm{ppm})=8.34(\mathrm{~s}$, $1 \mathrm{H}, \mathrm{NH}), 8.08(\mathrm{~d}, J=8.8 \mathrm{~Hz}, 2 \mathrm{H}, \mathrm{Ar}-\mathrm{H}), 7.72(\mathrm{~d}, J=7.9 \mathrm{~Hz}, 1 \mathrm{H}, \mathrm{Ar}-\mathrm{H}), 7.60(\mathrm{~d}, J=7.6 \mathrm{~Hz}, 2 \mathrm{H}$, Ar-H), 7.25 (s, 1H, Ar-H), 7.19-7.10 (m, 3H, Ar-H), 7.01 (dd, J = 8.1, 1.9 Hz, 1H, Ar-H), 6.66 $(\mathrm{d}, J=1.8 \mathrm{~Hz}, 1 \mathrm{H}, \mathrm{Ar}-\mathrm{H}), 4.77(\mathrm{~d}, J=11.1 \mathrm{~Hz}, 1 \mathrm{H}, \mathrm{COCH}), 4.58(\mathrm{t}, J=10.5 \mathrm{~Hz}, 1 \mathrm{H}, \mathrm{NCHCH})$, 4.15-4.07 (m, 1H, NCH), 3.59 (d, J = 14.9 Hz, 1H, SCH $2(\mathrm{a})), 3.53\left(\mathrm{~d}, J=14.7 \mathrm{~Hz}, 1 \mathrm{H}, \mathrm{SCH}_{2(\mathrm{~b})}\right)$,

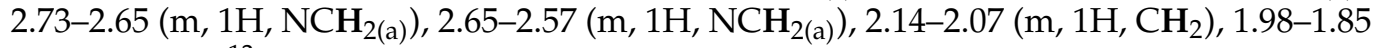
$\left(\mathrm{m}, 3 \mathrm{H}, \mathrm{CH}_{2}\right) ;{ }^{13} \mathrm{C}-\mathrm{NMR}\left(126 \mathrm{MHz} \mathrm{CDCl}_{3}\right): \delta(\mathrm{ppm})=195.7$ (CO), $180.4(\mathrm{CO}), 150.4,141.9$, $141.4,136.1,133.7,132.8,130.6,129.0,128.8,128.6,127.9,127.1,126.0,123.8,123.0,111.2$, $72.9,68.1,60.4,50.9,48.5,30.2,27.0,26.7\left(\mathrm{SCH}_{2}\right)$; IR $\left(\mathrm{KBr}, \mathrm{cm}^{-1}\right) v_{\max }=3112,3083,2967$, 2902, 2865, 1745, 1718, 1695, 1612, 1568, 1518, 1484, 1459, 1405, 1343, 1319, 1277, 1244, 1204, 1132, 1077, 1040, 864, 816, 765, 706, 626, 599; [Anal. Calcd. for $\mathrm{C}_{30} \mathrm{H}_{23} \mathrm{Cl}_{2} \mathrm{~N}_{3} \mathrm{O}_{4} \mathrm{~S}$ : C, 60.81; $\mathrm{H}$, 3.91; N, 7.09; Found: C, 61.01; H, 4.12; N, 7.19]; LC/MS (ESI, $m / z)$ : found $592.15\left[\mathrm{M}+\mathrm{H}^{+}\right]$. 2'-(4-Bromobenzoyl)-1'-(4-chloro-2H-thiochromen-3-yl)-5-fluoro- $1^{\prime}, 2^{\prime}, 5^{\prime}, 6^{\prime}, 7^{\prime}, 7 a^{\prime}$-hexahydrospiro[indoline-3,3'-pyrrolizin]-2-one $(7 \mathbf{h})$

(E)-1-(4-Bromophenyl)-3-(4-chloro-2H-thiochromen-3-yl)prop-2-en-1-one (4d) (196 mg, $0.5 \mathrm{mmol})$, L-proline (5) $(57.5 \mathrm{mg}, 0.5 \mathrm{mmol})$ and 5-fluoroisatin $(6 \mathrm{c})(83 \mathrm{mg}, 0.5 \mathrm{mmol})$ were reacted according to GP2 for 3-6 h and yielded white solid thio-chromen spirooxindole (7h) (241 mg, 79\%); m.p. $132-133{ }^{\circ} \mathrm{C} ;{ }^{1} \mathrm{H}-\mathrm{NMR}\left(400 \mathrm{MHz}, \mathrm{CDCl}_{3}\right): \delta(\mathrm{ppm})=8.45(\mathrm{~s}, 1 \mathrm{H}, \mathrm{NH})$, 7.72 (dd, J = 7.3, 2.0 Hz, 1H, Ar-H), 7.39 (s, 4H, Ar-H), 7.29-7.25 (m, 1H, Ar-H), 7.15 (dtd, $J=16.5,7.5,1.5 \mathrm{~Hz}, 2 \mathrm{H}, \mathrm{Ar}-\mathrm{H}), 6.98$ (dd, J = 8.1, 2.7 Hz, 1H, Ar-H), 6.86 (td, J = 8.7, 2.7 Hz, 1H, Ar-H), $6.67(\mathrm{dd}, J=8.8,4.4 \mathrm{~Hz}, 1 \mathrm{H}, \mathrm{Ar}-\mathrm{H}), 4.72(\mathrm{~d}, J=10.8 \mathrm{~Hz}, 1 \mathrm{H}, \mathrm{COCH}), 4.69$ (t, $J=11.2 \mathrm{~Hz}, 1 \mathrm{H}, \mathrm{NCHCH}), 4.43-4.22(\mathrm{~m}, 1 \mathrm{H}, \mathrm{NCH}), 3.64\left(\mathrm{~d}, J=14.8 \mathrm{~Hz}, 1 \mathrm{H}, \mathrm{SCH}_{2(\mathrm{a})}\right), 3.58(\mathrm{~d}$, $\left.J=14.8 \mathrm{~Hz}, 1 \mathrm{H}, \mathrm{SCH}_{2(\mathrm{~b})}\right), 3.02-2.88\left(\mathrm{~m}, 1 \mathrm{H}, \mathrm{NCH}_{2(\mathrm{a})}\right), 2.88-2.73\left(\mathrm{~m}, 1 \mathrm{H}, \mathrm{NCH}_{2(\mathrm{~b})}\right), 2.24-2.16$ $\left(\mathrm{m}, 1 \mathrm{H}, \mathrm{CH}_{2}\right), 2.17-1.95\left(\mathrm{~m}, 3 \mathrm{H}, \mathrm{CH}_{2}\right) ;{ }^{13} \mathrm{C}-\mathrm{NMR}\left(126 \mathrm{MHz} \mathrm{CDCl}_{3}\right): \delta(\mathrm{ppm})=195.5(\mathrm{CO})$, $180.8(\mathrm{CO}), 159.8 \& 157.9\left(\mathrm{~d}, J_{\mathrm{C} 1-\mathrm{F}}=242.8 \mathrm{~Hz}\right), 136.7,135.6,133.6,132.9,131.9,130.4,129.5$, 
$128.7,128.4,128.3,127.8,127.1,126.5 \& 126.5\left(\mathrm{~d}, J_{\mathrm{C} 3-\mathrm{F}}=7.31 \mathrm{~Hz}\right), 126.0,116.6 \& 116.4(\mathrm{~d}$, $\left.J_{\mathrm{C} 2-\mathrm{F}}=23.56 \mathrm{~Hz}\right), 115.8 \& 115.6\left(\mathrm{~d}, J_{\mathrm{C} 6-\mathrm{F}}=24.95 \mathrm{~Hz}\right), 111.0 \& 110.89\left(\mathrm{~d}, J_{\mathrm{C} 5-\mathrm{F}}=7.68 \mathrm{~Hz}\right)$, 73.7, 68.3, 59.6, 50.8, 48.4, 30.2, 27.1, $26.6\left(\mathrm{SCH}_{2}\right)$; IR $\left(\mathrm{KBr}, \mathrm{cm}^{-1}\right) v_{\max }=3355,3075,2973$, 2899, 2871, 2842, 1711, 1683, 1629, 1584, 1568, 1486, 1460, 1398, 1318, 1277, 1259, 1182, 1143, $1114,1070,1028,1007,988,948,899,852,814,760,721,685,631,594$; [Anal. Calcd. for $\mathrm{C}_{30} \mathrm{H}_{23} \mathrm{BrClFN}_{2} \mathrm{O}_{2} \mathrm{~S}$ : C, 59.08; H, 3.80; N, 4.59; Found: C, 58.97; H, 3.92; N, 4.43]; LC/MS (ESI, $m / z$ ): found $609.13\left[\mathrm{M}+\mathrm{H}^{+}\right]$.

2'-(4-Bromobenzoyl)-6-chloro-1'-(4-chloro-2H-thiochromen-3-yl)-1', $2^{\prime}, 5^{\prime}, 6^{\prime}, 7^{\prime}, 7 a^{\prime}$-hexahydrospiro[indoline-3,3'-pyrrolizin]-2-one (7i)

(E)-1-(4-Bromophenyl)-3-(4-chloro-2H-thiochromen-3-yl)prop-2-en-1-one (4d) (196 mg, $0.5 \mathrm{mmol})$, L-proline (5) $(57.5 \mathrm{mg}, 0.5 \mathrm{mmol})$ and 6-chloroisatin (6b) $(91 \mathrm{mg}, 0.5 \mathrm{mmol})$ were reacted according to GP2 for 3-6 h and yielded white solid thio-chromen spirooxindole (7i) (266 mg, 85\%); m.p. $105-106{ }^{\circ} \mathrm{C} ;{ }^{1} \mathrm{H}-\mathrm{NMR}\left(500 \mathrm{MHz}, \mathrm{CDCl}_{3}\right): \delta(\mathrm{ppm})=8.36(\mathrm{~s}, 1 \mathrm{H}, \mathrm{NH})$, $7.73(\mathrm{dd}, J=7.9,1.6 \mathrm{~Hz}, 1 \mathrm{H}, \mathrm{Ar}-\mathrm{H}), 7.43-7.34$ (m, 4H, Ar-H), 7.27-7.25 (m, 1H, Ar-H), 7.19 $(\mathrm{d}, J=8.1 \mathrm{~Hz}, 1 \mathrm{H}, \mathrm{Ar}-\mathrm{H}), 7.17(\mathrm{dd}, J=7.7,1.6 \mathrm{~Hz}, 1 \mathrm{H}, \mathrm{Ar}-\mathrm{H}), 7.13$ (td, $J=7.4,1.6 \mathrm{~Hz}, 1 \mathrm{H}$, Ar-H), 7.00 (dd, J = 8.1, 1.9 Hz, 1H, Ar-H), 6.69 (d, J = 1.9 Hz, 1H, Ar-H), 4.73 (d, J = 11.1 Hz, $1 \mathrm{H}, \mathrm{COCH}), 4.61$ (t, J = 9.5 Hz, 1H, NCHCH), 4.17-4.09 (m, 1H, NCH), 3.59 (d, J = 14.7 Hz, $\left.1 \mathrm{H}, \mathrm{SCH}_{2(\mathrm{a})}\right), 3.52\left(\mathrm{~d}, J=14.6 \mathrm{~Hz}, 1 \mathrm{H}, \mathrm{SCH}_{2(\mathrm{~b})}\right), 2.77-2.69\left(\mathrm{~m}, 1 \mathrm{H}, \mathrm{NCH}_{2(\mathrm{a})}\right), 2.65-2.60$ (m, $\left.1 \mathrm{H}, \mathrm{NCH}_{2(\mathrm{~b})}\right), 2.16-2.08\left(\mathrm{~m}, 1 \mathrm{H}, \mathrm{CH}_{2}\right), 1.98-1.86\left(\mathrm{~m}, 3 \mathrm{H}, \mathrm{CH}_{2}\right) ;{ }^{13} \mathrm{C}-\mathrm{NMR}\left(126 \mathrm{MHz}, \mathrm{CDCl}_{3}\right)$ : $\delta(\mathrm{ppm})=195.5(\mathrm{CO}), 180.6(\mathrm{CO}), 141.8,135.7,135.5,133.6,132.9,131.9,130.4,129.5,128.8$, 128.4, 128.3, 127.8, 127.0, 126.0, 123.1, 122.8, 111.0, 73.0, 68.2, 59.3, 50.9, 48.5, 30.1, 27.0, 26.6 $\left(\mathrm{SCH}_{2}\right)$; IR $\left(\mathrm{KBr}, \mathrm{cm}^{-1}\right) v_{\max }=3225,2958,2869,1726,1680,1613,1584,1484,1459,1436$, $1398,1323,1233,1206,1133,1072,1008,944,842,809,756,726,625,599 ;$ [Anal. Calcd. for $\mathrm{C}_{30} \mathrm{H}_{23} \mathrm{BrCl}_{2} \mathrm{~N}_{2} \mathrm{O}_{2} \mathrm{~S}$ : C, 57.52; H, 3.70; N, 4.47; Found: C, 57.63; H, 3.62; N, 4.39]; LC/MS (ESI, $m / z$ ): found $625\left[\mathrm{M}\left({ }_{35} \mathrm{Cl} /{ }_{79} \mathrm{Br}\right)+\mathrm{H}\right]^{+} ; 627.22\left[\mathrm{M}+\mathrm{H}^{+}\right]$.

2'-(4-Bromobenzoyl)-1'-(4-chloro-2H-thiochromen-3-yl)-5-nitro-1' $2^{\prime}, 5^{\prime}, 6^{\prime}, 7^{\prime}, 7 \mathrm{a}^{\prime}$-hexahydrospiro[indoline-3,3'-pyrrolizin]-2-one $(7 \mathbf{j})$

(E)-1-(4-Bromophenyl)-3-(4-chloro-2H-thiochromen-3-yl)prop-2-en-1-one (4d) (196 mg, $0.5 \mathrm{mmol}), \mathrm{L}$-proline (5) (57.5 mg, $0.5 \mathrm{mmol}$ ) and 5-nitroisatin (6e) (96 mg, $0.5 \mathrm{mmol})$ were reacted according to GP2 for 3-6 h and yielded light yellow solid thio-chromen spirooxindole (7j) (255 mg, 80\%); m.p. 120-121 ${ }^{\circ} \mathrm{C} ;{ }^{1} \mathrm{H}-\mathrm{NMR}\left(500 \mathrm{MHz}, \mathrm{DMSO}-d_{6}\right): \delta$ $(\mathrm{ppm})=11.10(\mathrm{~s}, 1 \mathrm{H}, \mathrm{NH}), 8.11(\mathrm{dd}, J=8.7,2.3 \mathrm{~Hz}, 1 \mathrm{H}, \mathrm{Ar}-\mathrm{H}), 7.90(\mathrm{~d}, J=2.4 \mathrm{~Hz}, 1 \mathrm{H}, \mathrm{Ar}-\mathrm{H})$, 7.68-7.64 (m, 1H, Ar-H), 7.53 (d, J = 8.6 Hz, 2H, Ar-H), 7.38 (d, J=8.6 Hz, 2H, Ar-H), 7.33 $(\mathrm{dd}, J=7.1,2.0 \mathrm{~Hz}, 1 \mathrm{H}, \mathrm{Ar}-\mathrm{H}), 7.27-7.19(\mathrm{~m}, 2 \mathrm{H}, \mathrm{Ar}-\mathrm{H}), 6.79$ (d, J = 8.7 Hz, 1H, Ar-H), 4.83 $(\mathrm{d}, J=10.8 \mathrm{~Hz}, 1 \mathrm{H}, \mathrm{COCH}), 4.49(\mathrm{t}, J=10.3 \mathrm{~Hz}, 1 \mathrm{H}, \mathrm{NCHCH}), 4.05-4.00(\mathrm{~m}, 1 \mathrm{H}, \mathrm{NCH}), 3.78$ $\left(\mathrm{d}, J=15.1 \mathrm{~Hz}, 1 \mathrm{H}, \mathrm{SCH}_{2(\mathrm{a})}\right), 3.71\left(\mathrm{~d}, J=15.1 \mathrm{~Hz}, 1 \mathrm{H}, \mathrm{SCH}_{2(\mathrm{~b})}\right), 2.68-2.63\left(\mathrm{~m}, 1 \mathrm{H}, \mathrm{NCH}_{2(\mathrm{a})}\right)$, 2.48-2.43 (m, 1H, NCH $\left.\mathrm{N}_{2(\mathrm{~b})}\right), 2.06-1.98\left(\mathrm{~m}, 1 \mathrm{H}, \mathrm{CH}_{2}\right), 1.94-1.89\left(\mathrm{~m}, 1 \mathrm{H}, \mathrm{CH}_{2}\right), 1.84-1.74(\mathrm{~m}$, 2H, $\left.\mathrm{CH}_{2}\right) ;{ }^{13} \mathrm{C}-\mathrm{NMR}\left(126 \mathrm{MHz}, \mathrm{DMSO}-d_{6}\right): \delta=196.2$ (CO), 179.1 (CO), 148.5, 141.7, 135.4, 133.6, 132.2, 131.6, 130.0, 129.6, 128.6, 128.3, 127.73, 127.1, 127.0, 126.9, 126.0, 125.3, 122.3, $110.1,71.8,67.2,59.3,50.3,47.7,29.1,26.3-\left(\mathrm{SCH}_{2}\right), 25.8 ; \mathrm{IR}\left(\mathrm{KBr}, \mathrm{cm}^{-1}\right) v_{\max }=3075,2978$, 2878, 2837, 1718, 1678, 1626, 1596, 1584, 1525, 1480, 1461, 1398, 1338, 1311, 1242, 1127, 1100, 1071, 997, 742, 856, 833, 755, 558; [Anal. Calcd. for $\mathrm{C}_{30} \mathrm{H}_{23} \mathrm{BrClN}_{3} \mathrm{O}_{4} \mathrm{~S}: \mathrm{C}, 56.57 ; \mathrm{H}, 3.64 ; \mathrm{N}$, 6.60; Found: C, 56.71; H, 3.55; N, 6.52]; LC/MS (ESI, $m / z$ ): found $636.10\left[\mathrm{M}+\mathrm{H}^{+}\right]$.

5-Chloro-1'-(4-chloro-2H-thiochromen-3-yl)-2'-(4-(trifluoromethyl)benzoyl)-1' , 2', 5' , , $6^{\prime}, 7^{\prime}, 7 \mathrm{a}^{\prime}$ hexahydrospiro[indoline-3,3'-pyrrolizin]-2-one (7k)

(E)-3-(4-Chloro-2H-thiochromen-3-yl)-1-(4-(trifluoromethyl)phenyl)prop-2-en-1-one (4e) (191 mg, $0.5 \mathrm{mmol})$, L-proline (5) (57.5 mg, $0.5 \mathrm{mmol}$ ) and 5-chloroisatin (6d) (91 mg, $0.5 \mathrm{mmol})$ were reacted according to GP2 for 3-6 h and yielded light yellow solid thiochromen spirooxindole (7k) (237 mg, 77\%); m.p. $141-142{ }^{\circ} \mathrm{C} ;{ }^{1} \mathrm{H}-\mathrm{NMR}\left(400 \mathrm{MHz}, \mathrm{CDCl}_{3}\right): \delta(\mathrm{ppm})=8.24(\mathrm{~s}$, $1 \mathrm{H}, \mathrm{NH}), 7.74(\mathrm{~d}, J=8.0 \mathrm{~Hz}, 1 \mathrm{H}, \mathrm{Ar}-\mathrm{H}), 7.61$ (d, J = 8.1 Hz, 2H, Ar-H), 7.53 (d, J = 8.2 Hz, 2H, Ar-H), 7.28 (d, J = 7.5 Hz, 1H, Ar-H), 7.20-7.08 (m, 4H, Ar-H), 6.63 (d, J = 8.5 Hz, 1H, Ar-H), $4.77(\mathrm{~d}, J=10.8 \mathrm{~Hz}, 1 \mathrm{H}, \mathrm{COCH}), 4.68(\mathrm{t}, J=10.4 \mathrm{~Hz}, 1 \mathrm{H}, \mathrm{NCHCH}), 4.44-4.22(\mathrm{~m}, 1 \mathrm{H}$, 
$\mathrm{NCH}), 3.66\left(\mathrm{~d}, J=14.8 \mathrm{~Hz}, 1 \mathrm{H}, \mathrm{SCH}_{2(\mathrm{a})}\right), 3.61\left(\mathrm{~d}, J=14.8 \mathrm{~Hz}, 1 \mathrm{H}, \mathrm{SCH}_{2(\mathrm{~b})}\right), 3.06-2.88(\mathrm{~m}$, $\left.1 \mathrm{H}, \mathrm{NCH}_{2(\mathrm{a})}\right), 2.88-2.72\left(\mathrm{~m}, 1 \mathrm{H}, \mathrm{NCH}_{2(\mathrm{~b})}\right), 2.25-2.16\left(\mathrm{~m}, 1 \mathrm{H}, \mathrm{CH}_{2}\right), 2.12-1.95\left(\mathrm{~m}, 3 \mathrm{H}, \mathrm{CH}_{2}\right)$; ${ }^{13} \mathrm{C}-\mathrm{NMR}\left(126 \mathrm{MHz}, \mathrm{CDCl}_{3}\right): \delta(\mathrm{ppm})=196.0(\mathrm{CO}), 180.4-(\mathrm{CO}), 139.7-, 139.2-, 133.6-, 132.9-$, 130.5, 130.0-, 128.5, 128.4, 128.3-, 128.2, 128.1, 127.9, 127.1, 126.6, 126.0, 125.6, 125.6, 124.6, $122.4,111.3,73.2,68.2,60.1,50.9,48.5,30.0,27.0,26.7\left(\mathrm{SCH}_{2}\right)$; IR $\left(\mathrm{KBr}, \mathrm{cm}^{-1}\right) v_{\max }=3078$, 2973, 2877, 2833, 1740, 1685, 1617, 1585, 1510, 1474, 1235, 1172, 1132, 1066, 1014, 1003, 950, 891, 863, 819, 761, 682, 626, 553; [Anal. Calcd. for $\mathrm{C}_{31} \mathrm{H}_{23} \mathrm{Cl}_{2} \mathrm{~F}_{3} \mathrm{~N}_{2} \mathrm{O}_{2} \mathrm{~S}: \mathrm{C}, 60.49 ; \mathrm{H}, 3.77 ; \mathrm{N}$, 4.55; Found: $\mathrm{C}, 60.67 ; \mathrm{H}, 3.85 ; \mathrm{N}, 4.66]$; LC/MS (ESI, $m / z)$ : found $615.18\left[\mathrm{M}+\mathrm{H}^{+}\right]$.

$1^{\prime}$-(4-Chloro-2H-thiochromen-3-yl)-5-nitro-2'-(4-(trifluoromethyl)benzoyl)-1' $2^{\prime} 2^{\prime}, 5^{\prime}, 6^{\prime}, 7^{\prime}, 7 \mathrm{a}^{\prime}$ hexahydrospiro[indoline-3,3'-pyrrolizin]-2-one (71)

(E)-3-(4-Chloro-2H-thiochromen-3-yl)-1-(4-(trifluoromethyl)phenyl)prop-2-en-1-one (4e) (191 mg, $0.5 \mathrm{mmol})$, L-proline (5) (57.5 mg, $0.5 \mathrm{mmol}$ ) and 5-nitroisatin (6e) $(96 \mathrm{mg}, 0.5 \mathrm{mmol})$ were reacted according to GP2 for 3-6 h and yielded light yellow solid thiochromen spirooxindole (71) $(235 \mathrm{mg}, 75 \%) ; \mathrm{m} . \mathrm{p} .139-140{ }^{\circ} \mathrm{C} ;{ }^{1} \mathrm{H}-\mathrm{NMR}\left(500 \mathrm{MHz}, \mathrm{DMSO}-d_{6}\right): \delta(\mathrm{ppm})=11.06$ (s, 1H, NH), $8.10(\mathrm{dd}, J=8.7,2.3 \mathrm{~Hz}, 1 \mathrm{H}, \mathrm{Ar}-\mathrm{H}), 7.91(\mathrm{~d}, J=2.3 \mathrm{~Hz}, 1 \mathrm{H}, \mathrm{Ar}-\mathrm{H}), 7.71-7.65$ $(\mathrm{m}, 3 \mathrm{H}, \mathrm{Ar}-\mathrm{H}), 7.61(\mathrm{~d}, J=8.3 \mathrm{~Hz}, 2 \mathrm{H}, \mathrm{Ar}-\mathrm{H}), 7.34(\mathrm{dd}, J=7.1,2.0 \mathrm{~Hz}, 1 \mathrm{H}$, Ar-H), 7.24 $(\mathrm{ddd}, J=9.0,7.3,1.7 \mathrm{~Hz}, 2 \mathrm{H}, \mathrm{Ar}-\mathrm{H}), 6.74(\mathrm{~d}, J=8.7 \mathrm{~Hz}, 1 \mathrm{H}, \mathrm{Ar}-\mathrm{H}), 4.91(\mathrm{~d}, J=10.8 \mathrm{~Hz}$, $1 \mathrm{H}, \mathrm{COCH}), 4.54-4.45(\mathrm{~m}, 1 \mathrm{H}, \mathrm{NCHCH}), 4.08-4.01(\mathrm{~m}, 1 \mathrm{H}, \mathrm{NCH}), 3.82(\mathrm{~d}, J=15.1 \mathrm{~Hz}, 1 \mathrm{H}$, $\left.\mathrm{SCH}_{2(\mathrm{a})}\right), 3.71\left(\mathrm{~d}, J=15.1 \mathrm{~Hz}, 1 \mathrm{H}, \mathrm{SCH}_{2(\mathrm{~b})}\right), 2.67-2.61\left(\mathrm{~m}, 1 \mathrm{H}, \mathrm{NCH}_{2(\mathrm{a})}\right), 2.49-2.44(\mathrm{~m}, 1 \mathrm{H}$, $\left.\mathrm{NCH}_{2(\mathrm{~b})}\right), 2.08-1.99\left(\mathrm{~m}, 1 \mathrm{H}, \mathrm{CH}_{2}\right), 1.95-1.88\left(\mathrm{~m}, 1 \mathrm{H}, \mathrm{CH}_{2}\right), 1.86-1.74\left(\mathrm{~m}, 2 \mathrm{H}, \mathrm{CH}_{2}\right) ;{ }^{13} \mathrm{C}$ NMR (126 MHz, DMSO-D $) \delta 196.6$ (CO), 179.0 (CO), 148.5, 141.8, 139.6, 133.6, 132.2, 130.0, 128.6, 128.5, 128.4, 127.1, 127.0, 126.0, 125.4, 125.2, 124.6, 122.4, 122.2, 110.2, 71.7, 67.3, 59.8, 50.2, 47.6, 29.2, $26.4\left(\mathrm{SCH}_{2}\right), 25.8$; IR $\left(\mathrm{KBr}, \mathrm{cm}^{-1}\right) v_{\max }=3075,2972,2875,2837,1737,1719$, 1688, 1625, 1598, 1526, 1480, 1461, 1409, 1339, 1325, 1171, 1130, 1102, 1066, 1014, 943, 903, 861, 835, 755, 721, 628, 556; [Anal. Calcd. for $\mathrm{C}_{31} \mathrm{H}_{23} \mathrm{ClF}_{3} \mathrm{~N}_{3} \mathrm{O}_{4} \mathrm{~S}$ : C, 59.47; $\mathrm{H}, 3.70 ; \mathrm{N}, 6.71$; Found: C, 59.38; H, 3.82; N, 8.63]; LC/MS (ESI, $m / z$ ): found $626.12\left[\mathrm{M}+\mathrm{H}^{+}\right]$.

$1^{\prime}$-(4-Chloro-2H-thiochromen-3-yl)-2'-(4-fluorobenzoyl)-1 ${ }^{\prime}, 2^{\prime}, 5^{\prime}, 6^{\prime}, 7^{\prime}, 7 \mathrm{a}^{\prime}$-hexahydrospiro[indoline-3,3'-pyrrolizin]-2-one (7m)

(E)-3-(4-Chloro-2H-thiochromen-3-yl)-1-(4-fluorophenyl)prop-2-en-1-one (4b) (164 mg, $0.5 \mathrm{mmol})$, L-proline (5) $(86 \mathrm{mg}, 0.75 \mathrm{mmol})$ and isatin $(6 \mathbf{a})(74 \mathrm{mg}, 0.5 \mathrm{mmol})$ were reacted according to GP2 for $2 \mathrm{~h}$ and yielded white solid thiochromen spirooxindole $(7 \mathrm{~m})(226 \mathrm{mg}$, 85\%); m.p.: $110-111{ }^{\circ} \mathrm{C} ;{ }^{1} \mathrm{H}-\mathrm{NMR}\left(400 \mathrm{MHz}, \mathrm{CDCl}_{3}\right): \delta(\mathrm{ppm})=8.32(\mathrm{~s}, 1 \mathrm{H}, \mathrm{NH}), 7.74(\mathrm{dd}$, $J=7.8,1.7 \mathrm{~Hz}, 1 \mathrm{H}, \mathrm{Ar}-\mathbf{H}), 7.50$ (dd, $J=8.7,5.3 \mathrm{~Hz}, 2 \mathrm{H}, \mathrm{Ar}-\mathbf{H}), 7.30-7.21(\mathrm{~m}, 2 \mathrm{H}, \mathrm{Ar}-\mathbf{H}), 7.15$ $(\mathrm{ddd}, J=19.9,9.2,7.3 \mathrm{~Hz}, 3 \mathrm{H}, \mathrm{Ar}-\mathrm{H}), 6.99(\mathrm{t}, J=7.7 \mathrm{~Hz}, 1 \mathrm{H}, \mathrm{Ar}-\mathrm{H}), 6.89(\mathrm{t}, J=8.7 \mathrm{~Hz}, 2 \mathrm{H}$, Ar-H), $6.66(\mathrm{~d}, J=7.9 \mathrm{~Hz}, 1 \mathrm{H}, \mathrm{Ar}-\mathrm{H}), 4.73(\mathrm{~d}, J=10.8 \mathrm{~Hz}, 1 \mathrm{H}, \mathrm{COCH}), 4.69(\mathrm{t}, J=10.8 \mathrm{~Hz}, 1 \mathrm{H}$, $\mathrm{NCHCH}), 4.30-4.20(\mathrm{~m}, 1 \mathrm{H}, \mathrm{NCH}), 3.64\left(\mathrm{~d}, J=14.8 \mathrm{~Hz}, 1 \mathrm{H}, \mathrm{SCH}_{2(\mathrm{a})}\right), 3.56(\mathrm{~d}, J=14.8 \mathrm{~Hz}$, $\left.1 \mathrm{H}, \mathrm{SCH}_{2(\mathrm{~b})}\right), 2.93-2.80\left(\mathrm{~m}, 1 \mathrm{H}, \mathrm{NCH}_{2(\mathrm{a})}\right), 2.77-2.69\left(\mathrm{~m}, 1 \mathrm{H}, \mathrm{NCH}_{2(\mathrm{~b})}\right), 2.17-2.12(\mathrm{~m}, 1 \mathrm{H}$, $\left.\mathrm{CH}_{2}\right), 2.07-1.91\left(\mathrm{~m}, 3 \mathrm{H}, \mathrm{CH}_{2}\right) ;{ }^{13} \mathrm{C}-\mathrm{NMR}\left(101 \mathrm{MHz}, \mathrm{CDCl}_{3}\right): \delta(\mathrm{ppm})=195.11(\mathrm{CO}), 181.00$ $(\mathrm{CO}), 166.73 \& 164.70\left(\mathrm{~d}, J_{\mathrm{C} 1-\mathrm{F}}=255.78 \mathrm{~Hz}\right), 140.65,133.62,133.44,133.04,130.69 \& 130.62$ $\left(\mathrm{d}, J_{\mathrm{C} 3-\mathrm{F}}=9.20 \mathrm{~Hz}\right), 130.17,129.80,128.83,128.34,127.84,127.78,127.05,125.91,124.86$, $122.78,115.65 \& 115.48\left(\mathrm{~d}, J_{\mathrm{C} 2-\mathrm{F}}=21.80 \mathrm{~Hz}\right), 110.30,68.42,59.61,50.74,48.52,30.29,27.02$, $26.68\left(\mathrm{SCH}_{2}\right)$; IR $\left(\mathrm{KBr}, \mathrm{cm}^{-1}\right) v_{\max }=3187,3145,3074,2963,2872,1718,1689,1620,1596$, 1504, 1471, 1461, 1435, 1408, 1388, 1322, 1297, 1263, 1234, 1207, 1184, 1155, 1105, 951, 853", 797, 761, 751, 722, 604; [Anal. Calcd. for $\mathrm{C}_{30} \mathrm{H}_{24} \mathrm{ClFN}_{2} \mathrm{O}_{2} \mathrm{~S}: \mathrm{C}, 67.85 ; \mathrm{H}, 4.56$; N, 5.28; Found: C, 67.73; H, 4.45; N, 5.16]; LC/MS (ESI, $m / z)$ : found $531.24[\mathrm{M}+\mathrm{H}]^{+}$.

\subsection{Biological Activity Assays Protocols}

Cytotoxicity against BJ human fibroblast normal cell line against PC3, HeLa, MCF-7 and MDA-MB231 cancer cell lines were evaluated by following the procedure as described in the literature [55-59] (Supplementary Materials). 


\section{Results and Discussion}

\subsection{Synthesis of (4a-e) and (7a-m)}

Three steps synthesis of the target compounds are presented in Schemes 1 and 2. The first step was to synthesize 4-chloro-2H-thiochromene-3-carbaldehyde (2) which is required to prepare chalcone based thiochromene scaffolds (4a-e) (Scheme 1). The second step is a three-component reaction in which the 1,3-dipolar cycloaddition key-reaction between thiochromene based-chalcone and the azomethine ylides, generated the substituted isatins (6a-e) (Isatin (6a), 5-chloroisatin (6b), 6-chloroisatin (6c), 5-fluoroisatin (6d), and 5-nitroisatin (6e) and amino acid L-proline (5) (Scheme 2). Thus, the diversity points in our library are the substituents at the isatin ring, and the aromatic substituents in the thiochromene based-chalcone. All three component reactions were carried out by heating an equimolar mixture of the thiochromene based-chalcone, isatin derivative, and L-proline in $\mathrm{MeOH}$ under reflux conditions for 3-6 h. After completion of the reaction as checked by TLC, the solvent was evaporated and the cyclized spiro-compounds were purified by column chromatography to afford pure cycloadducts in a very good yield. The following aromatic substituents in the thiochromene based-chalcone in the para-position $\left(\mathrm{Cl}, \mathrm{F}, \mathrm{NO}_{2}\right.$, $\mathrm{Br}$, and $\mathrm{CF}_{3}$ ) were employed to explore the substrate scope, and to establish generality of this approach. The structures of the spirooxindoles $(7 \mathrm{a}-\mathrm{m})$ were assigned based on spectrophotometric tools including ${ }^{1} \mathrm{H}-\&{ }^{13} \mathrm{C}-\mathrm{NMR}$, MS and IR spectral analyses which have been found with a high constituency with the proposed chemical structures. Additionally, compound $(7 \mathrm{~m})$ was obtained in crystalline form suited for single crystal X-ray diffraction analysis. The final cycloadducts were obtained in excellent regio-selectivity and diastereo-selectivity. The reaction mechanism assumed to proceed via two steps shown in Scheme 3. The first step is to generate the azomethine yields by the reaction of isatins with L-proline to afford the cyclic lactone, followed by decarboxylation. The cycloaddition step-2 occurs in a such way as to make the two carbonyls of the oxindole ring and the chalcone moiety trans to each other to minimize the steric repulsion in the final product. Besides, the stereochemistry of the stereo-genic centers is unambiguously confirmed by single crystal X-ray analysis for compound $(7 \mathrm{~m})$ as a representative example. ${ }^{1} \mathrm{H}-\mathrm{NMR}$ spectrum showed the assigned protons and matched with the proposed structure. A singlet at $\delta 8.32$ was assigned to the $\mathrm{NH}$ proton. The signals occurred at $\delta 7.74-6.66$ were assigned for the aromatic protons while the protons of the fused pyrrolidine ring were assigned at $\delta$ 4.73-1.91. The two protons of the methine group adjacent to the sulfur atom of the thiochromene ring were observed at $\delta 3.64$ and 3.56. ${ }^{13} \mathrm{C}$-NMR spectrum showed the characteristic carbon signals of the proposed compound. IR spectrum showed the desired final compound's functionalities and the functional groups disappeared as active carbon in isatin derivatives, as well as the olefin functional group in the chalcones.
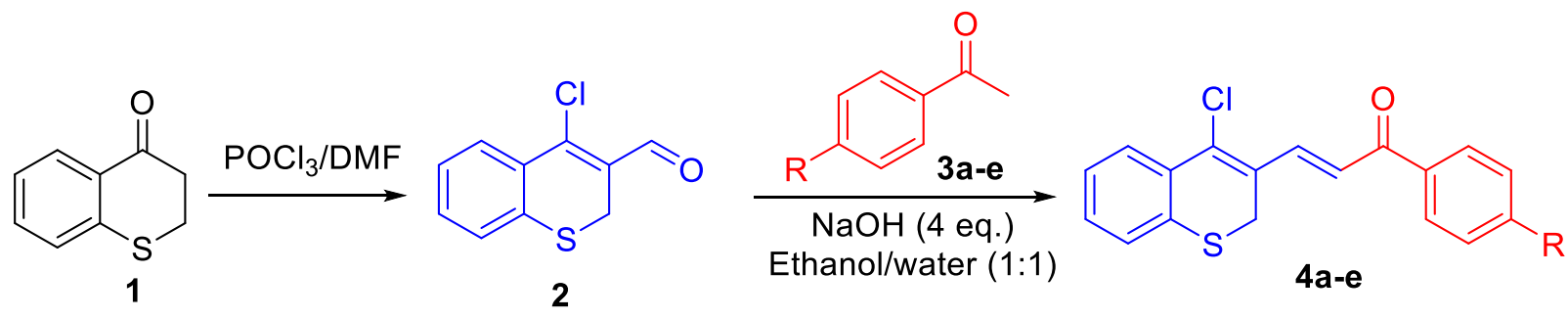

$$
\begin{aligned}
& \text { 4a; } \mathrm{R}=\mathrm{Cl} ; \mathbf{4 b} ; \mathrm{R}=\mathrm{F} \\
& \text { 4c; } \mathrm{R}=\mathrm{NO}_{2} ; 4 \mathbf{d} ; \mathrm{R}=\mathrm{Br} \\
& \text { 4e; } \mathrm{R}=\mathrm{CF}_{3}
\end{aligned}
$$

Scheme 1. Synthesis of chalcone grafted $2 H$-thiochromenes (4a-e). 
<smiles>[R7]c1ccc(C(=O)/C=C/C2=C(Cl)c3ccccc3SC2)cc1</smiles>

4a-e

4a; $\mathrm{R}=\mathrm{Cl} ; \mathbf{4 b} ; \mathrm{R}=\mathrm{F}$

4c; $\mathrm{R}=\mathrm{NO}_{2} ; 4 \mathrm{~d} ; \mathrm{R}=\mathrm{Br}$;

$4 \mathbf{e} ; \mathrm{R}=\mathrm{CF}_{3}$<smiles>[R]Cc1cc2c(cc1[R])C(=O)C(=O)N2</smiles>

6a-e

Isatin 6a

6-Chloroisatin $\mathbf{6 b}$

5-Fluoroisatin 6c

5-Chloroisatin 6d

5-Nitroisatin 6e

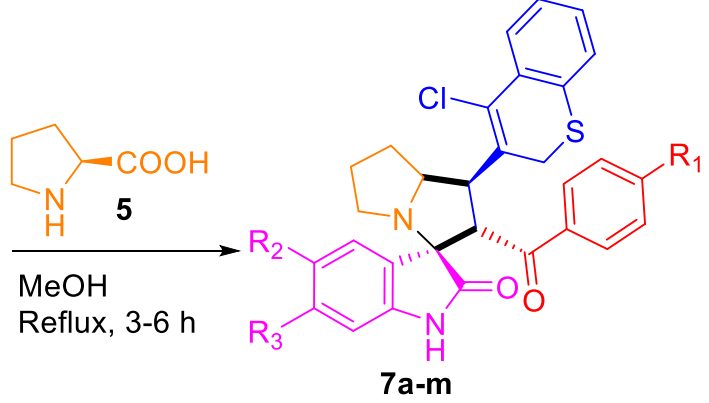

$7 \mathrm{a} ; \mathrm{R}_{1}=\mathrm{Cl}, \mathrm{R}_{2}=\mathrm{H}, \mathrm{R}_{3}=\mathrm{H}$

7b; $\mathrm{R}_{1}=\mathrm{Cl}, \mathrm{R}_{2}=\mathrm{H}, \mathrm{R}_{3}=\mathrm{Cl}$

7c; $R_{1}=C l, R_{2}=F, R_{3}=H$

7d; $R_{1}=F, R_{2}=F, R_{3}=H$

7e; $R_{1}=F, R_{2}=H, R_{3}=\mathrm{Cl}$

7f; $R_{1}=N_{2}, R_{2}=F, R_{3}=H$

7g; $R_{1}=N_{2}, R_{2}=H, R_{3}=\mathrm{Cl}$

7h; $R_{1}=B r, R_{2}=F, R_{3}=H$

$7 i ; R_{1}=B r, R_{2}=H, R_{3}=C l$

$7 \mathrm{j} ; \mathrm{R}_{1}=\mathrm{Br}, \mathrm{R}_{2}=\mathrm{NO}_{2}, \mathrm{R}_{3}=\mathrm{H}$

$7 \mathbf{k} ; \mathrm{R}_{1}=\mathrm{CF}_{3}, \mathrm{R}_{2}=\mathrm{Cl}, \mathrm{R}_{3}=\mathrm{H}$

7l; $R_{1}=C_{3}, R_{2}=N_{2}, R_{3}=H$

$7 \mathrm{~m} ; \mathrm{R}_{1}=\mathrm{CF}_{3}, \mathrm{R}_{2}=\mathrm{H}, \mathrm{R}_{3}=\mathrm{H}$

Scheme 2. Synthesis of spirooxindoles $(7 \mathrm{a}-\mathrm{m})$ based the thiochromene scaffold.

Proposed approach of 1,3-dipole to dipolarophile, explaining the regio- and diastereoselective Synthesis.

\section{1}<smiles>[R][R]1ccc2c(c1)NC(=O)C2=O</smiles>

6a-e<smiles>O=C(O)C1CCCN1</smiles>

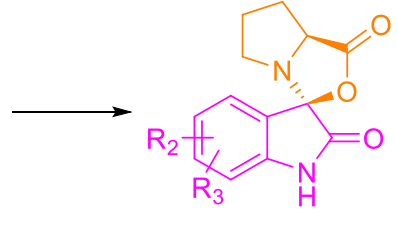

Intermediate<smiles>C#CCOC(C)(C)C</smiles><smiles>[R]CC[R]([R])=c1[nH]c(=O)c(=C2CCCC2)c2ccccc12</smiles>

Azomethine Yilde (AY)

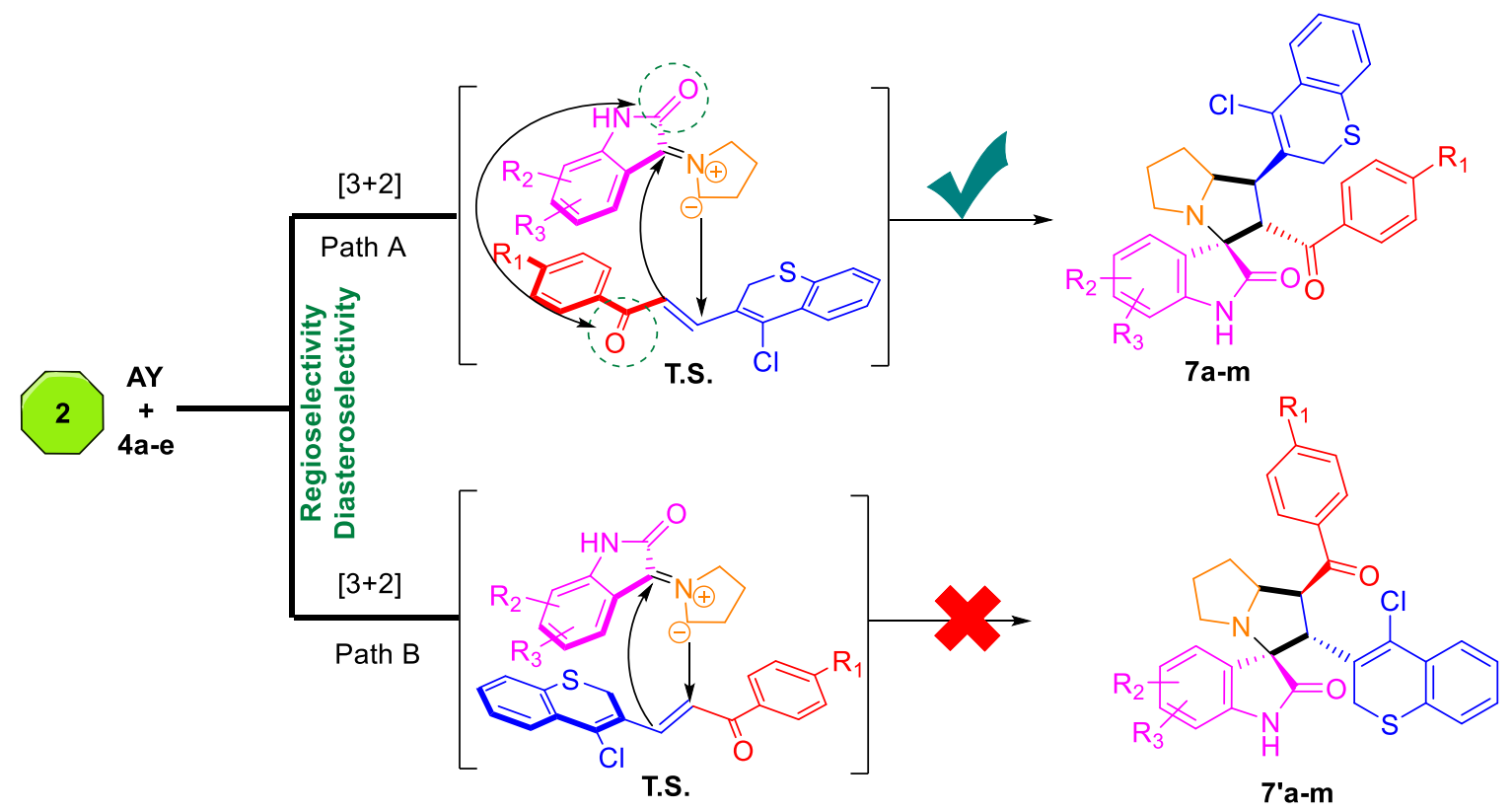

Scheme 3. Proposed mechanism for the regio- and diastereo-selective synthesis of the spirooxindole (7a-m) based thiochromene scaffold. 


\subsection{X-ray Structure Description}

The X-ray structure of $(7 \mathbf{m})$, crystallized in the monoclinic crystal system and of centrosymmetric $\mathrm{C} 2 / \mathrm{c}$ space group, with eight molecular units per unit cell was elucidated. The unit cell parameters are $a=36.6524(7) \AA, b=8.27830$ (10) $\AA, c=17.1963(3) \AA$, $102.216(2)^{\circ}$ and $V=5099.55(15) \AA^{3}$. The X-ray structure was in agreement with the spectral characterization and the formation of the spiro system of the compound (Figure 2). The two spiro-moieties (oxindole and pyrolizine) are linked together via the C15 asymmetric center. The thiochromene moiety was also found to be connected to the pyrolizine via the $\mathrm{C} 10$ chiral carbon. The molecular units of this compound form a dimer via noncovalent interactions (Figure 3). In this figure two molecules of $(7 \mathbf{m})$ are connected via $\mathrm{N}-\mathrm{H} \ldots \mathrm{O}$ hydrogen bonding interactions. Crystal data and structure refinement for compound $(7 \mathrm{~m})$ are listed in Table 1 . Selected bond lengths $[\AA ̊]$ and angles $\left[{ }^{\circ}\right]$ for $(7 \mathbf{m})$ are summarized in Table 2.

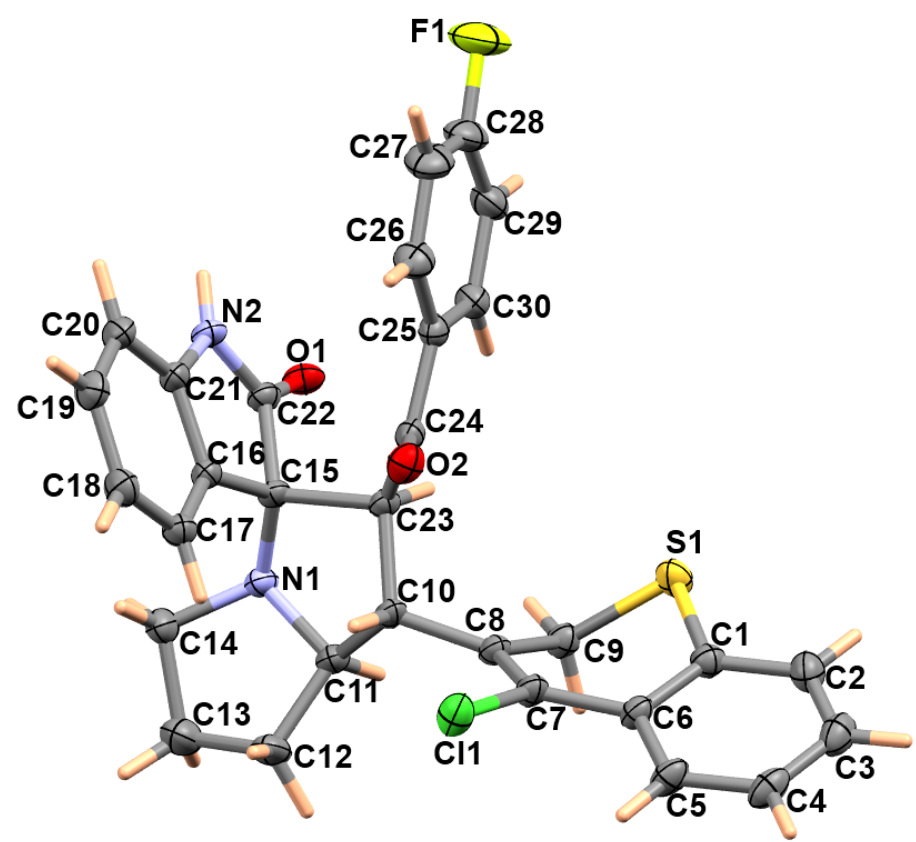

Figure 2. Thermal ellipsoids are showing atom numbering for the X-ray structure of compound (7m).

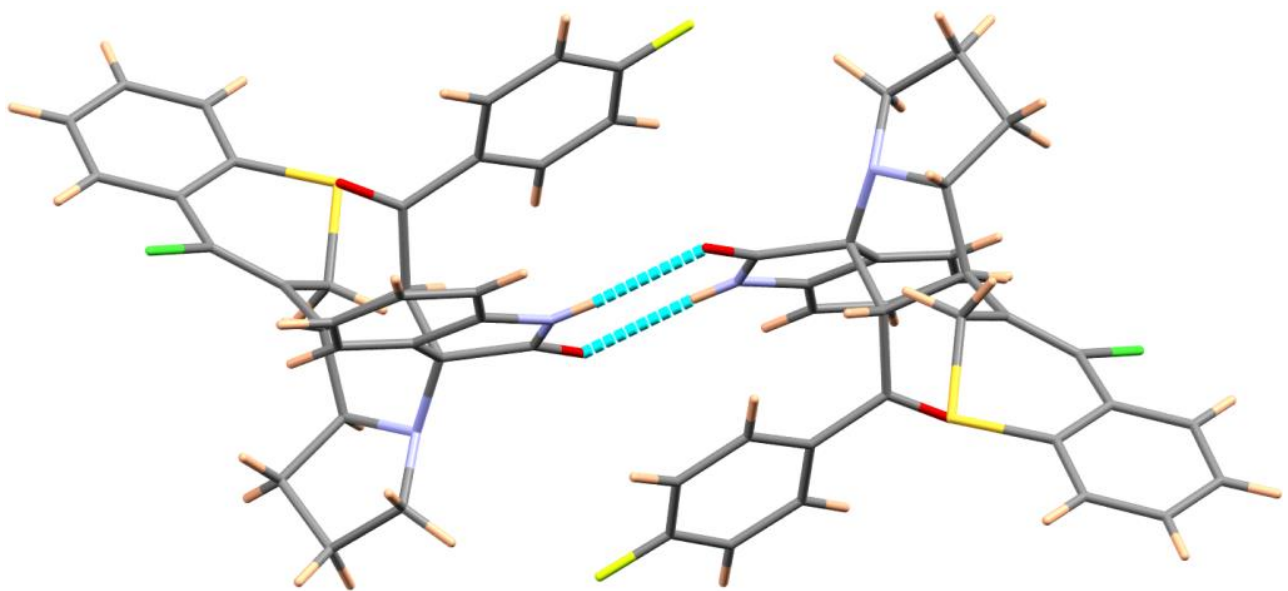

Figure 3. Hydrogen bonding interactions in compound (7m). 
Table 1. Crystal data and structure refinement for compound $(7 \mathbf{m})$. Hydrogen bond details: $N(2)$ $\mathrm{H}(2): 0.80(2) \AA ; \mathrm{H}(2) \ldots \mathrm{O}(1)^{\# 1}: 2.08(2) \AA ; \mathrm{N}\left(2 \ldots \mathrm{O}(1)^{\# 1}: 2.877(1) \AA\right.$ and $\mathrm{N}(2)-\mathrm{H}(2) \ldots \mathrm{O}(1)^{\# 1}: 174(2)^{\circ}$ and the symmetry code is ${ }^{\# 1}-\mathrm{x}+1,-\mathrm{y}+1,-\mathrm{z}+1$.

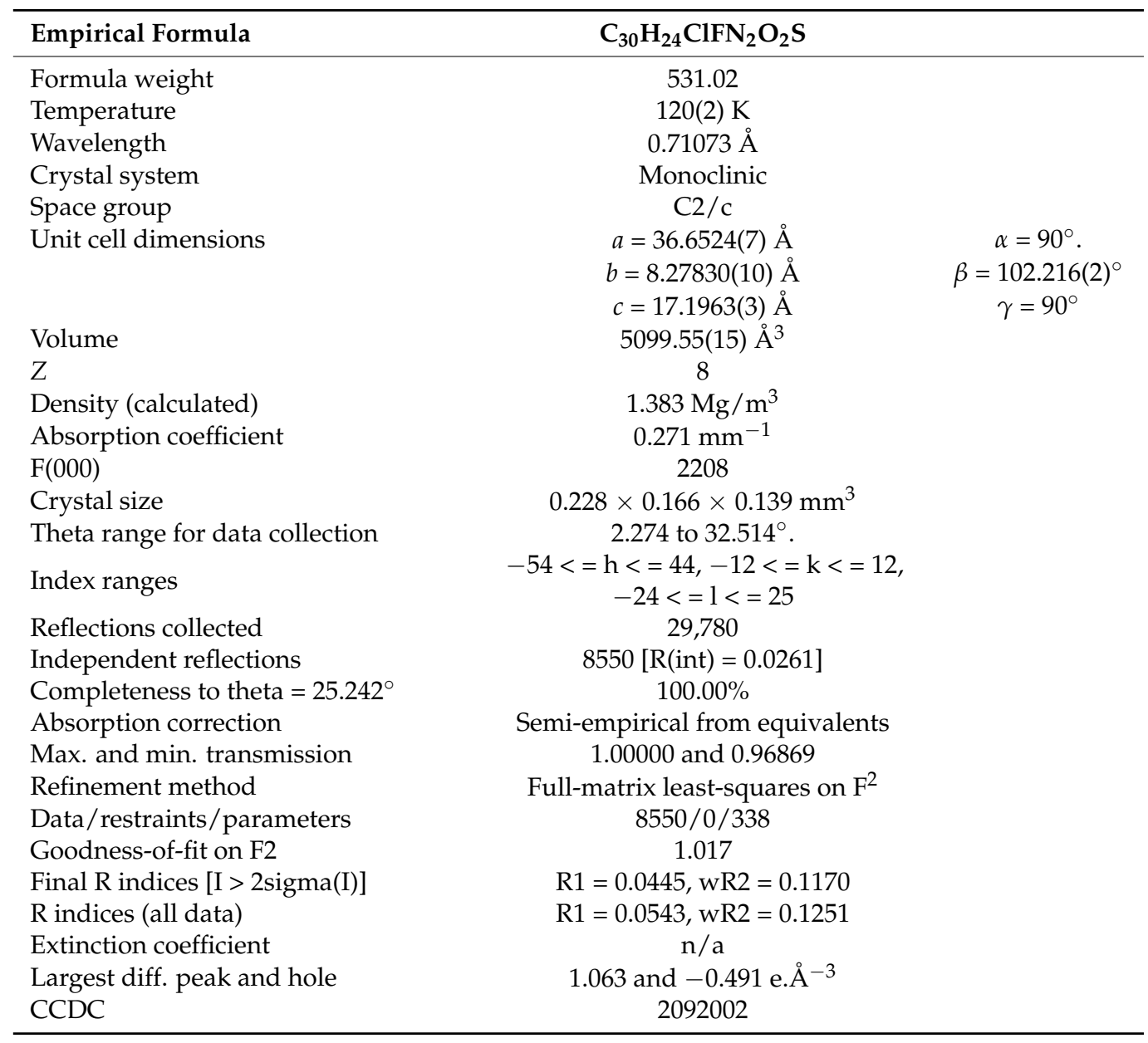

Table 2. Selected bond lengths $[\AA]$ and angles $\left[{ }^{\circ}\right]$ for compound $(7 \mathbf{m})$.

\begin{tabular}{llll}
\hline Atoms & Distance & Atoms & Distance \\
\hline $\mathrm{Cl}(1)-\mathrm{C}(7)$ & $1.7480(13)$ & $\mathrm{N}(1)-\mathrm{C}(15)$ & $1.4555(17)$ \\
$\mathrm{S}(1)-\mathrm{C}(1)$ & $1.7554(14)$ & $\mathrm{N}(1)-\mathrm{C}(14)$ & $1.4765(17)$ \\
$\mathrm{S}(1)-\mathrm{C}(9)$ & $1.8027(14)$ & $\mathrm{N}(1)-\mathrm{C}(11)$ & $1.4919(16)$ \\
$\mathrm{O}(1)-\mathrm{C}(22)$ & $1.2272(16)$ & $\mathrm{N}(2)-\mathrm{C}(22)$ & $1.3534(17)$ \\
$\mathrm{O}(2)-\mathrm{C}(24)$ & $1.2169(16)$ & $\mathrm{N}(2)-\mathrm{C}(21)$ & $1.4052(17)$ \\
$\mathrm{F}(1)-\mathrm{C}(28)$ & $1.3556(18)$ & & \\
Atoms & Angle & Atoms & Angle \\
$\mathrm{C}(1)-\mathrm{S}(1)-\mathrm{C}(9)$ & $96.20(6)$ & $\mathrm{C}(5)-\mathrm{C}(6)-\mathrm{C}(1)$ & $117.89(12)$ \\
$\mathrm{C}(15)-\mathrm{N}(1)-\mathrm{C}(14)$ & $119.17(11)$ & $\mathrm{C}(5)-\mathrm{C}(6)-\mathrm{C}(7)$ & $122.18(12)$ \\
$\mathrm{C}(15)-\mathrm{N}(1)-\mathrm{C}(11)$ & $110.27(10)$ & $\mathrm{C}(1)-\mathrm{C}(6)-\mathrm{C}(7)$ & $119.72(11)$ \\
$\mathrm{C}(14)-\mathrm{N}(1)-\mathrm{C}(11)$ & $109.32(10)$ & $\mathrm{C}(8)-\mathrm{C}(7)-\mathrm{C}(6)$ & $124.07(12)$ \\
\hline
\end{tabular}

\subsection{Biological Activity}

All chalcones-based-thiochromenes (4a-e), and the spirooxindole/pyrrolidine/thiochromenes (7a-m) were initially examined for their toxicity against the human fibroblast BJ normal cell line. The results depicted in Table 1 indicated that all the synthesized compounds were non-toxic, except compounds (7d) and (7k) which appeared to be slightly toxic at $30 \mu \mathrm{M}$ concentration. The toxicities of these two compounds may be due to the 
presence of $\mathrm{F}_{2} \mathrm{CF}_{3}$ and $\mathrm{Cl}$ substituents at the phenyl ring-based chalcone, and the chlorine atom attached to $\mathrm{C}-5$ incorporated isatin moiety.

The antiproliferative activity against four human cancer lines, including prostate PC-3, cervical HeLa, and breast (MCF-7 and MDA-MB231) were evaluated by MTT assay [55-59] and the results were compared with the standard anti-cancer drug doxorubicin as a reference.

MCF-7 is a human breast cancer cell line with glucocorticoid, progesterone and estrogen receptors it is widely used worldwide for in vitro anti-cancer assay. The cell line is known to retain mammary epithelial characteristics, particularly estrogen (the first hormone to respond to breast cancer) processing via estrogen receptors [60,61]. In contrast the MDA-MB-231 cell line is particularly used to model late stage cancer, and is considered to be a good triple negative model because of the lack of growth factor receptor HER2 and absence of ER, PR, and E-cadherin [62].

All chalcones-based thiochromenes (4a-e) were found to be inactive against PC-3, HeLa, MCF-7, and MDA-MB231 cell lines, except 4-fluoro and 4-nitro substituted phenyl moiety containing compounds $(4 \mathbf{b})\left(\mathrm{IC}_{50}=27.7 \pm 0.9 \mu \mathrm{M}\right)$ and $(4 \mathbf{c})\left(\mathrm{IC}_{50}=27.7 \pm 0.9 \mu \mathrm{M}\right)$, which appeared to be weakly active against PC-3 cervical cancer cell line.

The results of antiproliferative activity against the prostate cancer PC 3 cell line by the spiro-oxindole/pyrrolidine/thiochromene series $(7 \mathrm{a}-\mathrm{m})$ showed that the most active hybrid in these series was compound $(7 \mathrm{f})\left(\mathrm{IC}_{50}=8.7 \pm 0.7 \mu \mathrm{M}\right)$, having para- $\mathrm{NO}_{2}$ aromatic substituent, and the fluorine at C-5 of the isatin ring, whereas complete loss of activity was observed for compound $(7 \mathrm{~g})$ having a chlorine atom at $\mathrm{C}-5$ of the isatin ring. The replacement of para- $\mathrm{NO}_{2}$ with para-bromo at the aromatic ring also contributed towards a decrease in activity, as observed for compounds $(7 \mathrm{~h})\left(\mathrm{IC}_{50}=16 \pm 0.7 \mu \mathrm{M}\right)$. Further decrease in activity was observed for compounds with 4-chloro $\left(7 \mathbf{i}, \mathrm{IC}_{50}=27.7 \pm 0.9 \mu \mathrm{M}\right)$ and 5-nitro $\left(7 \mathbf{j}, \mathrm{IC}_{50}=22.5 \pm 0.4 \mu \mathrm{M}\right)$ groups, attached to the isatin ring. Present of a chlorine atom at $\mathrm{C}$ 6 of the isatin ring, in combination with the para-fluoro-substituted benzene ring, decreased the activity of compounds $\left(7 \mathrm{e}, \mathrm{IC}_{50}=27.5 \pm 0.5 \mu \mathrm{M}\right)$, and $\left(7 \mathbf{i}, \mathrm{IC}_{50}=27.7 \pm 0.9 \mu \mathrm{M}\right)$ against PC-3 cells. On the other hand, compound (7k) with a chlorine atom at C-5 at the isatin ring and $p$-trifluoromethyl benzene appeared to be the second most active member of the series $\left(\mathrm{IC}_{50}=15.6 \pm 0.3 \mu \mathrm{M}\right)$, whereas replacement of the C-5 chlorine isatin ring with C-5 nitro isatin moiety resulted in a complete loss of activity, as observed in compound 71 . Compounds ( $7 \mathrm{a}-\mathrm{d}, 7 \mathrm{~g}, 7 \mathrm{l}$, and $7 \mathrm{~m})$ were not active.

Next, the anticancer assay against cervical cancer HeLa cell line exhibited moderate to weak anticancer activity in comparison to the standard drug doxorubicin $\left(\mathrm{IC}_{50}=0.9 \pm\right.$ $0.14 \mu \mathrm{M})$. The most potent spirooxindole/pyrrolidine/thiochromene hybrid (7k) having C-5 chlorine incorporated isatin moiety with $p$-trifluoromethyl phenyl ring gave the best results with $\mathrm{IC}_{50}=8.4 \pm 0.5 \mu \mathrm{M}$, followed by $\mathrm{C}-4$ chlorine incorporated isatin and $p$-nitro phenyl moieties containing $\left(7 \mathrm{~g}, \mathrm{IC}_{50}=10.4 \pm 0.7 \mu \mathrm{M}\right)$. The replacement of $\mathrm{C}-4$ chlorine containing isatin moiety with C-5 fluoro isatin led to a decrease in anti-cancer potential of (7f, $\left.\mathrm{IC}_{50}=22.6 \pm 0.1 \mu \mathrm{M}\right)$ against HeLa cell line, found to be further decreased in compound $\left(7 \mathbf{h}, \mathrm{IC}_{50}=25.3 \pm 0.25 \mu \mathrm{M}\right)$, containing $p$-bromo-phenyl ring instead of $p$-nitro phenyl moiety, whereas a sharp increase in activity was observed for adduct $\left(7 \mathbf{j}, \mathrm{IC}_{50}=12.0 \pm 0.1 \mu \mathrm{M}\right)$ having C-5 nitro isatin instead of C-5 fluoro isatin( $\left.7 \mathrm{~h}, \mathrm{IC}_{50}=25.3 \pm 0.25 \mu \mathrm{M}\right)$. Complete loss of activity was observed for compound (7e) having a $p$-fluorophenyl ring instead of $p$-nitrophenyl $\left(7 \mathrm{~g}, \mathrm{IC}_{50}=10.4 \pm 0.7 \mu \mathrm{M}\right),(7 \mathbf{i})$ having a C-5 chloro isatin ring instead of C-6 nitro isatin $\left(7 \mathbf{j}, \mathrm{IC}_{50}=12.0 \pm 0.1 \mu \mathrm{M}\right)$, and (7l) having a C-6 nitro isatin ring instead of C-6 chloro isatin moiety $\left(7 \mathbf{k}, \mathrm{IC}_{50}=8.4 \pm 0.5 \mu \mathrm{M}\right)$. Comparison of compound (7a) with $(7 \mathrm{~m})$, which have $\mathrm{IC}_{50}=24.8 \pm 0.3 \mu \mathrm{M}$ and $18.5 \pm 0.9 \mu \mathrm{M}$, respectively, indicated slight improvement in the reactivity due to the replacement of the chlorine atom with fluorine.

Many of the tested chalcones-based-thiochromenes (4a-e), and the spirooxindole/pyrrolidine/thiochromenes (7a-m) appeared to be inactive against MCF-7 and MDA-MB231 breast cancer cell lines, except (7d-f, $7 \mathbf{h}$, and $7 \mathbf{k})$. C-5 fluoro incorporated isatin moiety with $p$-fluoro phenyl ring containing (7d) appeared as the most potent against MCF-7 $\left(\mathrm{IC}_{50}=7.36 \pm 0.37 \mu \mathrm{M}\right)$ and MDA-MB231 $\left(\mathrm{IC}_{50}=9.44 \pm 0.32 \mu \mathrm{M}\right)$ breast cancer cell lines 
A slight decrease in activity against both cell lines was observed in compound (7h, MCF$7, \mathrm{IC}_{50}=8.34 \pm 0.64 \mu \mathrm{M}$, and MDA-MB231, $\mathrm{IC}_{50}=11.25 \pm 0.28 \mu \mathrm{M}$ ) having a $p$-fluoro phenyl ring instead of a $p$-bromo phenyl ring. The observed anti-cancer potential in-case of compound (7h) was further decreased in compound (7e, MCF-7, $\mathrm{IC}_{50}=16.4 \pm 0.61 \mu \mathrm{M}$ and MDA-MB231, $\mathrm{IC}_{50}=21.29 \pm 1.35 \mu \mathrm{M}$ ) having $\mathrm{C}-4$ chloro incorporated isatin moiety with $p$-fluoro phenyl ring and C-5 chloro isatin with $p$-trifluoromethyl phenyl moieties containing (7k, MCF-7, $\mathrm{IC}_{50}=26.04 \pm 1.07 \mu \mathrm{M}$, and MDA-MB231, $\mathrm{IC}_{50}=25.28 \pm 0.77 \mu \mathrm{M}$ ). On the other hand, substitution of $p$-nitro group on the phenyl ring together with C-5 fluoro incorporated isatin moiety contributed towards a drastic increase in anti-cancer potential against MDA-MB231 cell line $\left(\mathrm{IC}_{50}=9.29 \pm 0.34 \mu \mathrm{M}\right)$ and slight increase in anticancer activity against MCF-7 cell line $\left(\mathrm{IC}_{50}=23.27 \pm 0.80 \mu \mathrm{M}\right)$, as observed in $(7 \mathbf{f})$, whereas, in comparison to (7f), the replacement of C-5 fluoro incorporated isatin moiety with 4choloro isatin ring contributed towards a considerable increase in activity of compound $(7 \mathrm{~g})$ against MCF-7 $\left(\mathrm{IC}_{50}=14.3 \pm 0.16 \mu \mathrm{M}\right)$, and a complete loss of activity against MDAMB231 breast cancer cell line. Compound (7m) of $p$-F-atom on the phenyl ring without any substitution on the isatin core structure showed a weak activity for both breast cancer cell lines (MCF-7; $\mathrm{IC}_{50}=24.16 \pm 0.25 \mu \mathrm{M}$ and MDA-MB231; $\left.\mathrm{IC}_{50}=21.09 \pm 0.1 \mu \mathrm{M}\right)$. All results are summarized in Table 3.

Table 3. Results of cytotoxicity assay against BJ (normal), and PC3, HeLa, MCF-7, and MDA-MB231 (cancer) cell lines for the synthesized chalcones (4a-e), and spirooxindoles (7a-m).

\begin{tabular}{|c|c|c|c|c|c|c|}
\hline \multirow[b]{2}{*}{ Compounds } & \multirow[b]{2}{*}{$\begin{array}{c}\text { Chemical Structure } \\
\text { 4a-e/7a-m }\end{array}$} & \multicolumn{5}{|c|}{ Cancer Type/Cell Line $\left(\mathrm{IC}_{50}, \mu \mathrm{M}\right)$} \\
\hline & & $\begin{array}{c}\text { Human } \\
\text { Fibroblast } \\
\text { BJ }\end{array}$ & $\begin{array}{l}\text { Prostate } \\
\text { PC3 }\end{array}$ & $\begin{array}{l}\text { Cervical } \\
\text { HeLa }\end{array}$ & $\begin{array}{r}\text { Breast } \\
\text { MCF-7 }\end{array}$ & $\begin{array}{c}\text { Breast } \\
\text { MDA-MB231 }\end{array}$ \\
\hline $4 a$ & & NA & NA & NA & NA & NA \\
\hline $4 b$ & & NA & NA & $19.3 \pm 0.3$ & NA & NA \\
\hline $4 c$ & & NA & NA & $19.7 \pm 0.7$ & NA & NA \\
\hline $4 d$ & & NA & NA & NA & NA & NA \\
\hline $4 e$ & & NA & NA & NA & NA & NA \\
\hline
\end{tabular}


Table 3. Cont.

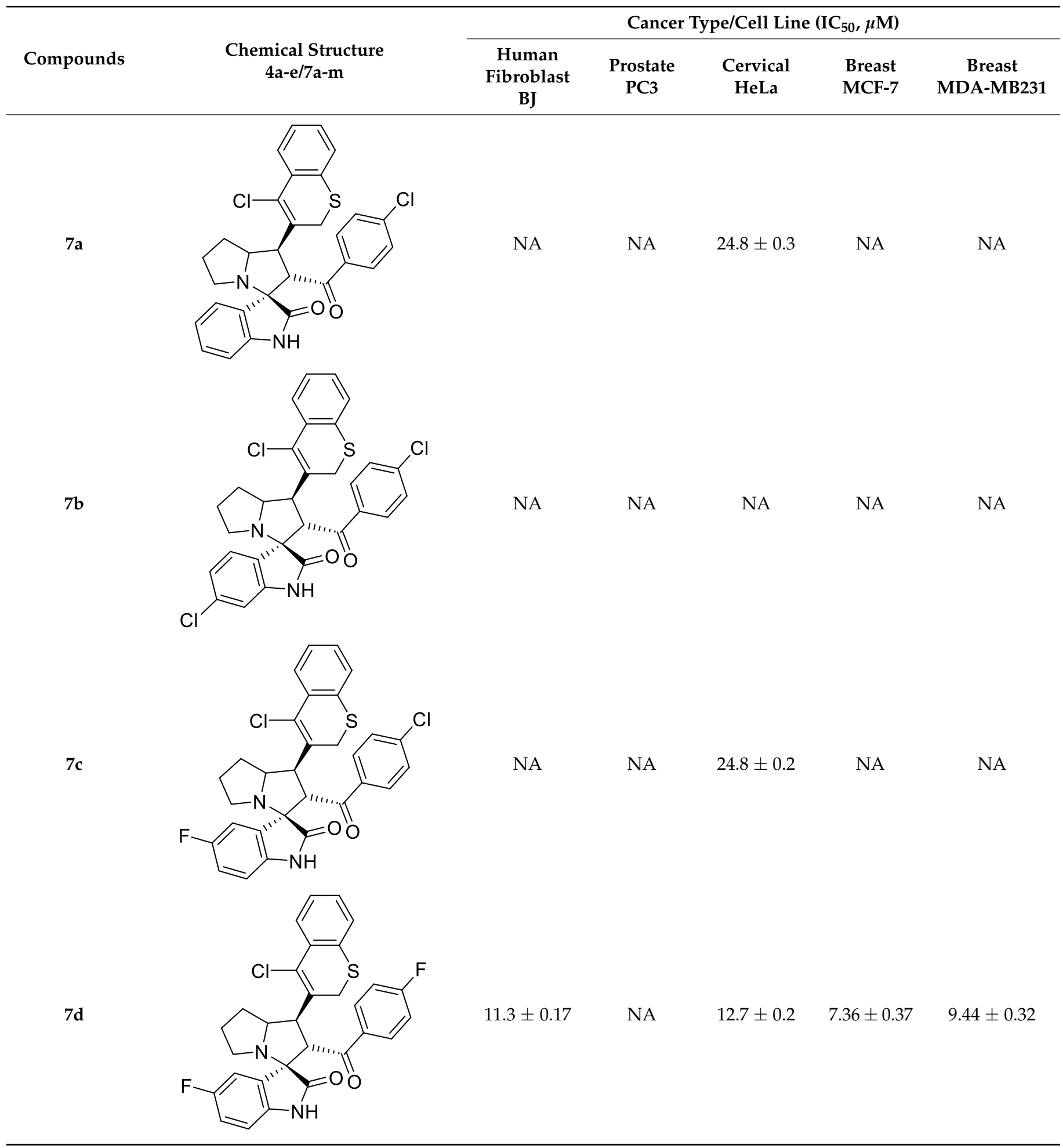


Table 3. Cont.

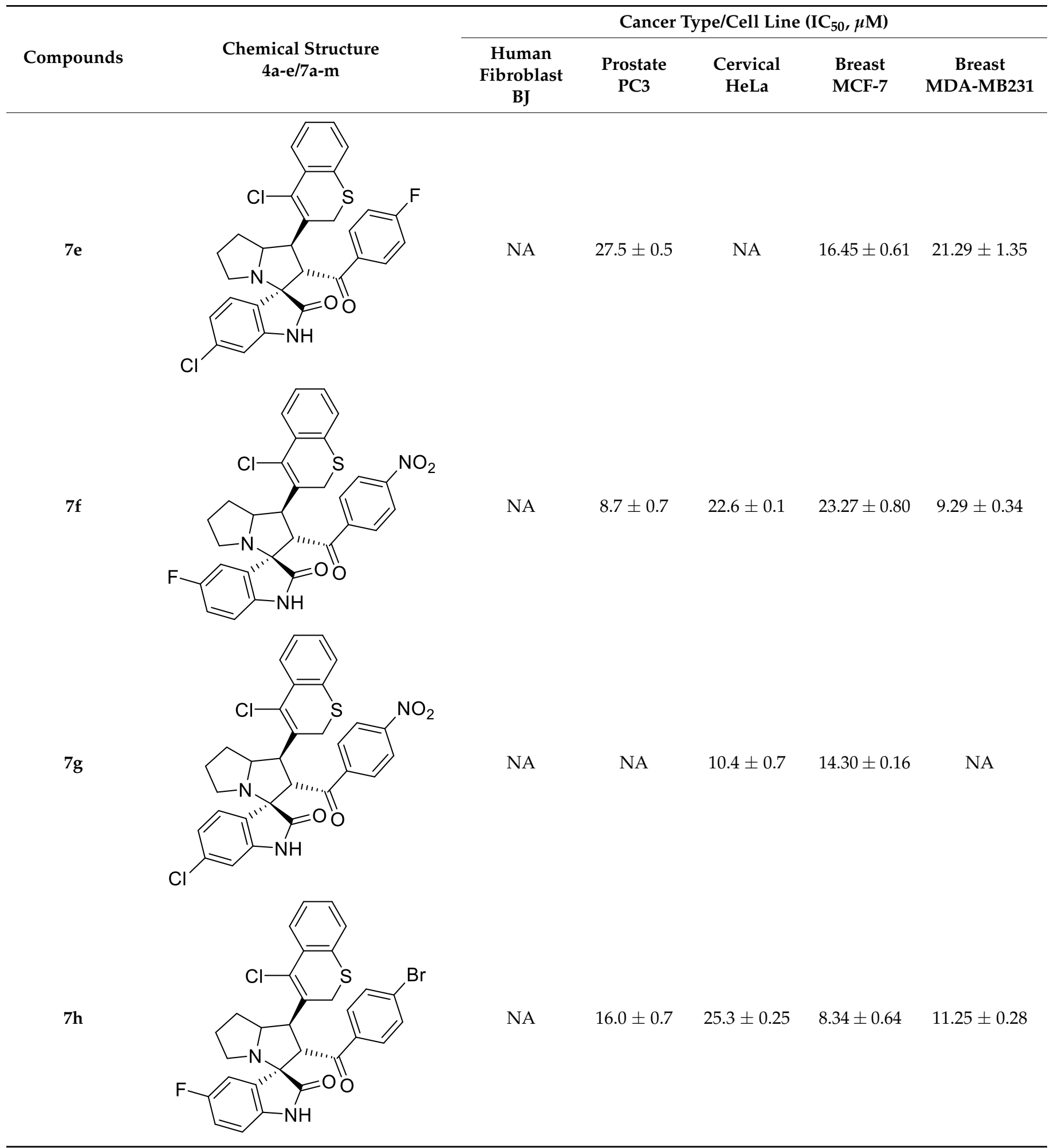


Table 3. Cont.

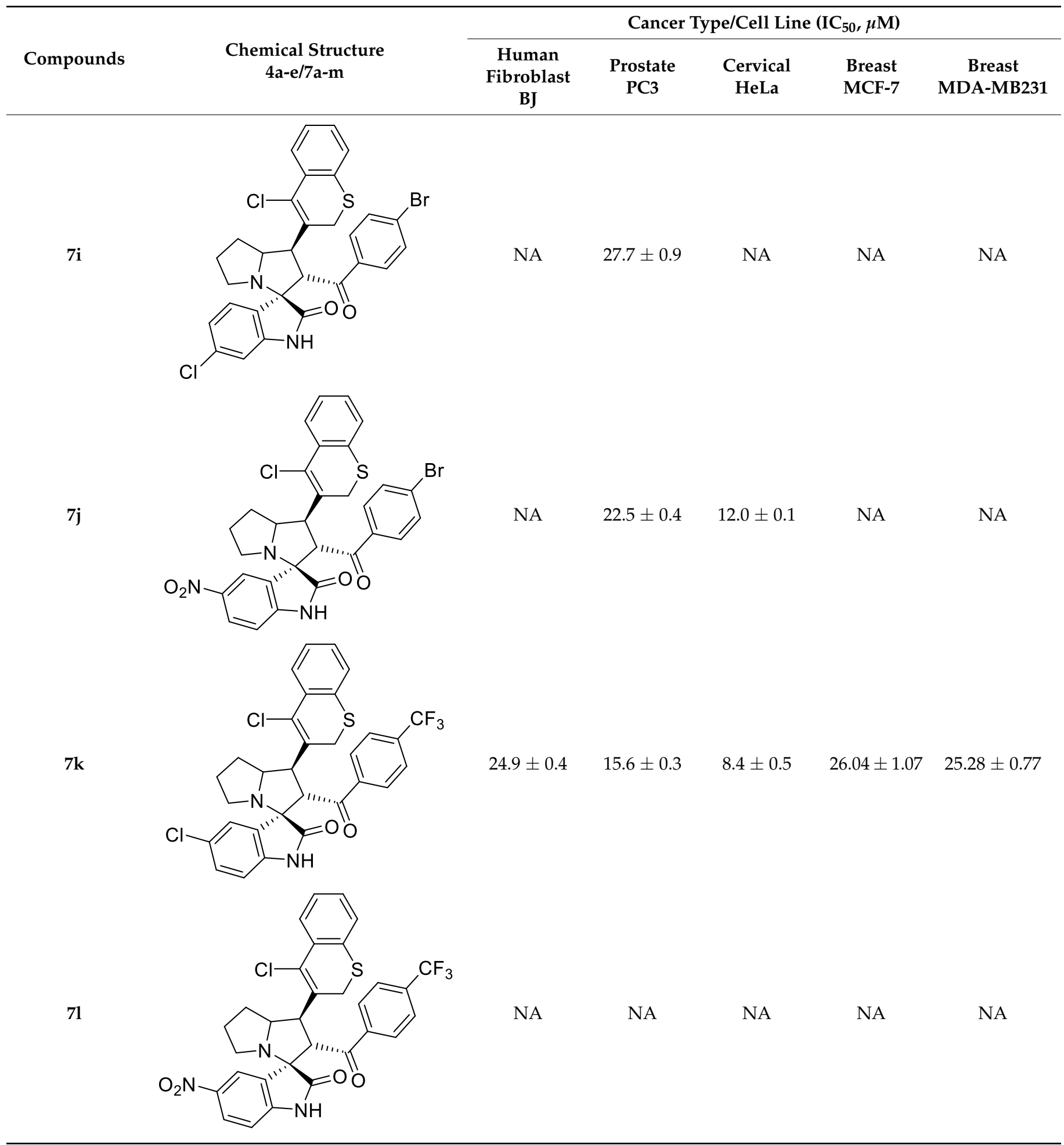


Table 3. Cont.

\begin{tabular}{|c|c|c|c|c|c|c|}
\hline \multirow[b]{2}{*}{ Compounds } & \multirow[b]{2}{*}{$\begin{array}{c}\text { Chemical Structure } \\
\text { 4a-e/7a-m }\end{array}$} & \multicolumn{5}{|c|}{ Cancer Type/Cell Line $\left(\mathrm{IC}_{50}, \mu \mathrm{M}\right)$} \\
\hline & & $\begin{array}{c}\text { Human } \\
\text { Fibroblast } \\
\text { BJ }\end{array}$ & $\begin{array}{l}\text { Prostate } \\
\text { PC3 }\end{array}$ & $\begin{array}{l}\text { Cervical } \\
\text { HeLa }\end{array}$ & $\begin{array}{l}\text { Breast } \\
\text { MCF-7 }\end{array}$ & $\begin{array}{c}\text { Breast } \\
\text { MDA-MB231 }\end{array}$ \\
\hline $7 \mathrm{~m}$ & & NA & NA & $18.5 \pm 0.9$ & $24.16 \pm 0.25$ & $21.09 \pm 0.1$ \\
\hline STD. & Doxorubicin & $\mathrm{N} / \mathrm{A}$ & $1.9 \pm 0.4$ & $0.9 \pm 0.14$ & $0.79 \pm 0.05$ & $0.32 \pm 0.002$ \\
\hline
\end{tabular}

$\mathrm{IC}_{50}(\mu \mathrm{M})$ was evaluated using MTT assay and \pm is the standard deviation from three independent experiments. NA: the tested compound did not show anticancer activity at $30 \mu \mathrm{M}$.

\section{Conclusions}

During this study we have successfully achieved the synthesis of a new library of hybrid based spirooxindole/pyrrolidine/thiochromenes (7a-m) by three-component 1,3dipolar cycloaddition reactions in complete regio- and stereo-selective fashion. The anticancer assay showed promising results as good candidates for further studies. Compounds (7f, $\left.\mathrm{IC}_{50}=8.7 \pm 0.7 \mu \mathrm{M}\right)$ exhibited more potent activity against $\mathrm{PC} 3$, whereas hybrid $(7 \mathbf{k})$ was most active against cervical cancer HeLa $\left(\mathrm{IC}_{50} 8.4 \pm 0.5 \mu \mathrm{M}\right)$ and for breast cancer MCF-7 cell lines $\left(7 \mathbf{d}, \mathrm{IC}_{50}=7.36 \pm 0.37 \mu \mathrm{M}\right)$, whereas $\left(7 \mathrm{~d}, \mathrm{IC}_{50}=9.44 \pm 0.32 \mu \mathrm{M}\right)$ also appeared more active against MDA-MB231 breast cancer cell line. The mechanism of action and in vivo study will be considered in the near future to further validate results of in vitro assays.

Supplementary Materials: The following are available online at https: / /www.mdpi.com/article/ 10.3390/sym13081426/s1, Figures S1-S18: ${ }^{1} \mathrm{H}-\mathrm{NMR}$ and ${ }^{13} \mathrm{C}-\mathrm{NMR}$ for compounds 4a-e and 7a-m along with the $\mathrm{X}$-ray structure determinations and biological activity assays protocols are provided in SI.

Author Contributions: Conceptualization, A.B. and M.I.C.; methodology, M.S.I., M.A., A.M.A.-M., S.A. and A.S.A.; validation, M.S.I., M.A., A.M.A.-M., S.A. and A.S.A.; formal analysis, M.S.I., M.A., A.M.A.-M., S.A. and A.S.A.; investigation, M.S.I., M.A., A.M.A.-M., S.A. and A.S.A.; resources, A.B.; data curation, M.S.I., M.A., A.M.A.-M., S.A. and A.S.A.; writing-original draft preparation, A.B. and S.Y.; writing-review and editing, M.I.C.; visualization, A.B. and M.I.C.; project administration, M.A.; funding acquisition, A.B.; All authors have read and agreed to the published version of the manuscript.

Funding: King Abdulaziz City for Science and Technology, Kingdom of Saudi Arabia, Award Number (14-BIO128-02).

Institutional Review Board Statement: Not applicable.

Informed Consent Statement: Not applicable.

Data Availability Statement: The data presented in this study are available in Supplementary Material.

Acknowledgments: This Project was funded by the National Plan for Science, Technology and Innovation (MAARIFAH), King Abdulaziz City for Science and Technology, Kingdom of Saudi Arabia, Award Number (14-BIO128-02). The authors would like to thank Matti Haukka (Department of Chemistry, University of Jyväskylä, Finland) for solved the structure of compound $7 \mathbf{m}$ by single crystal X-ray diffraction analysis. 
Conflicts of Interest: The authors declare no conflict of interest.

\section{References}

1. Uma, R.G.; Vivek Kumar, S.; Bharkavi, C.; Menendez, J.C.; Perumal, S. One-pot access to a library of dispiro oxindolepyrrolidine/pyrrolothiazole-thiochromane hybrids via three-component 1, 3-dipolar cycloaddition reactions. ACS Comb. Sci. 2016, 18, 337-342.

2. Cui, C.B.; Kakeya, H.; Osada, H. Novel mammalian cell cycle inhibitors, spirotryprostatins A and B, produced by Aspergillus fumigatus, which inhibit mammalian cell cycle at G2/M phase. Tetrahedron 1996, 52, 12651-12666. [CrossRef]

3. Cui, C.B.; Kakeya, H.; Osada, H. Spirotryprostatin B, novel mammalian cell cycle inhibitor produced by Aspergillus fumigatus. J Antibiot. 1996, 49, 832-835. [CrossRef]

4. Ban, Y.; Taga, N.; Oishi, T. The synthesis of 3-spirooxindole derivatives. Total syntheses of dl-formosanine, dl-isoformosanine, dl-mitraphylline and dl-isomitraphylline. Tetrahedron Lett. 1974, 15, 187-190. [CrossRef]

5. Anderton, N.; Cockrum, P.A.; Colegate, S.M.; Edgar, J.A.; Flower, K.; Vit, I.; Willing, R.I. Oxindoles from Phalariscoe rulescens. Phytochemistry 1998, 48, 437-439. [CrossRef]

6. Pellegrin, C.; Weber, M.; Borschberg, H.-J. Total synthesis of (+)-elacomine and (-)-isoelacomine, two hitherto unnamed oxindole alkaloids from Elaeagnus commutata. Helv. Chim. Acta. 1996, 79, 151-168. [CrossRef]

7. Jossang, A.; Jossang, P.; Hadi, H.A.; Sevenet, T.; Bodo, B. Horsfiline, an oxindole alkaloid from Horsfieldia superba. J. Org. Chem. 1991, 56, 6527-6530. [CrossRef]

8. Chan, K.C.; Morsingh, F.; Yeoh, G. Alkaloids of Uncaria pteropoda. Isolation and structures of pteropodine and isopteropodine. J. Chem. Soc. C 1966, 1966, 2245-2249. [CrossRef] [PubMed]

9. Ghedira, K.; Zeches-Hanrot, M.; Richard, B.; Massiot, G.; Le MenOlivier, L.; Sevenet, T.; Goh, S.H. Alkaloids of Alstonia angustifolia. Phytochemistry 1988, 27, 3955-3962. [CrossRef]

10. Shi, J.S.; Yu, J.X.; Chen, X.P.; Xu, R.X. Pharmacological actions of Uncaria alkaloids, rhynchophylline and isorhynchophylline. Acta. Pharmacol. Sin. 2003, 24, 97-101.

11. Bassleer, R.; Depauw-Gillet, M.C.; Massart, B.; Marnette, J.-M.; Wiliquet, P.; Caprasse, M.; Angenot, L. Effets de trois alcalóides extraits du Strychnos usambarensis sur des cellules cancéreuses en culture. Planta Med. 1982, 45, 123-126. [CrossRef]

12. Suresh Kumar, R.; Michael Rajesh, S.; Perumal, S.; Banerjee, D.; Yogeeswari, P.; Sriram, D. Novel three-component domino reactions of ketones, isatin and amino acids: Synthesis and discovery of antimycobacterial activity of highly functionalised novel dispiropyrrolidines. Eur. J. Med. Chem. 2010, 45, 411-422. [CrossRef] [PubMed]

13. Michael, R.S.; Perumal, S.; Menendez, J.C.; Yogeeswari, P.; Sriram, D. Antimycobacterial activity of spirooxindolo-pyrrolidine, pyrrolizine and pyrrolothiazole hybrids obtained by a three component regio- and stereo-selective 1,3-dipolar cycloaddition. Med. Chem. Commun. 2011, 2, 626-630.

14. Bhaskar, G.; Arun, Y.; Balachandran, C.; Saikumar, C.; Perumal, P.T. Synthesis of novel spirooxindole derivatives by one pot multicomponent reaction and their antimicrobial activity. Eur. J. Med. Chem. 2012, 51, 79-91. [CrossRef] [PubMed]

15. Kornet, M.J.; Thio, A.P. Oxindole-3-spiropyrrolidines and -piperidines. Synthesis and local anesthetic activity. J. Med. Chem. 1976, 19, 892-898. [CrossRef] [PubMed]

16. Yu, B.; Yu, D.-Q.; Liu, H.-M. Spirooxindoles: Promising scaffolds for anticancer agents. Eur. J. Med. Chem. 2015, 97, 673-698. [CrossRef] [PubMed]

17. Zhao, Y.; Yu, S.; Sun, W.; Liu, L.; Lu, J.; McEachern, D.; Shargary, S.; Bernard, D.; Li, X.; Zhao, T.; et al. A potent small-molecule inhibitor of the MDM2-p53 interaction (MI-888) achieved complete and durable tumor regression in mice. J. Med. Chem. 2013, 56, 5553-5561. [CrossRef]

18. Ghosh, R.; Vitor, J.B.; Mendes, E.; Paulo, A.; Acharya, P.C. Stereoselective synthesis of spirooxindole derivatives using one-pot multicomponent cycloaddition reaction and evaluation of their antiproliferative efficacy. ACS Omega. 2020, 5, 27332-27343. [CrossRef]

19. Zhou, R.; Wu, Q.; Guo, M.; Huang, W.; He, X.; Yang, L.; Peng, F.; He, G.; Han, B. Organocatalytic cascade reaction for the asymmetric synthesis of novel chroman-fused spirooxindoles that potently inhibit cancer cell proliferation. Chem. Commun. 2015, 51, 13113-13116. [CrossRef]

20. Yu, B.; Yu, Z.; Qi, P.; Yu, D.; Liu, H. Discovery of orally active anticancer candidate CFI-400945 derived from biologically promising spirooxindoles: Success and challenges. Eur. J. Med. Chem. 2015, 95, 35-40. [CrossRef]

21. Yang, J.; Hu, Y.; Li, Q.; Yu, F.; Cao, J.; Fang, D.; Huang, Z.; Shi, D. Efficient and regioselective synthesis of novel functionalized dispiropyrrolidines and their cytotoxic activities. ACS Comb. Sci. 2014, 16, 139-145. [CrossRef] [PubMed]

22. Kidwai, M.; Jain, A.; Nemaysh, V.; Kumar, R.; Luthra, P.M. Efficient entry to diversely functionalized spirooxindoles from isatin and their biological activity. Med. Chem. Res. 2013, 22, 2717-2723. [CrossRef]

23. Zhao, Y.; Liu, L.; Sun, W.; Lu, J.; McEachern, D.; Xiaoqin, L.; Yu, S.; Bernard, D.; Ochsenbein, P.; Ferey, V.; et al. Diastereomeric spirooxindoles as highly potent and efficacious MDM2 inhibitors. J. Am. Chem. Soc. 2013, 135, 7223-7234. [CrossRef] [PubMed]

24. Barakat, A.; Soliman, S.M.; Alshahrani, S.; Islam, M.S.; Ali, M.; Al-Majid, A.M.; Yousuf, S. Synthesis, X-ray single crystal, conformational analysis and cholinesterase inhibitory activity of a new spiropyrrolidine scaffold tethered benzo[b]thiophene analogue. Crystals 2020, 10, 120. [CrossRef] 
25. Barakat, A.; Alshahrani, S.; Al-Majid, A.M.; Ali, M.; Altowyan, M.S.; Islam, M.S.; Alamary, A.S.; Ashraf, S.; Ul-Haq, Z. Synthesis of a new class of spirooxindole-benzo[b]thiophene-based molecules as acetylcholinesterase inhibitors. Molecules 2020, $25,4671$. [CrossRef]

26. Barakat, A.; Islam, M.S.; Ghawas, H.M.; Al-Majid, A.M.; El-Senduny, F.F.; Badria, F.A.; Elshaier, Y.A.; Ghabbour, H.A. Design and synthesis of new substituted spirooxindoles as potential inhibitors of the MDM2-p53 interaction. Bioorg. Chem. 2019, 86, 598-608. [CrossRef]

27. Altowyan, M.S.; Barakat, A.; Al-Majid, A.M.; Al-Ghulikah, H.A. Spiroindolone analogues bearing benzofuran moiety as a selective cyclooxygenase COX-1 with TNF- $\alpha$ and IL-6 inhibitors. Saudi. J. Biol. Sci. 2020, 27, 1208-1216. [CrossRef]

28. Altowyan, M.S.; Barakat, A.; Al-Majid, A.M.; Al-Ghulikah, H. Spiroindolone analogues as potential hypoglycemic with dual inhibitory activity on $\alpha$-amylase and $\alpha$-glucosidase. Molecules 2019, 24, 2342. [CrossRef] [PubMed]

29. Islam, M.S.; Ghawas, H.M.; El-Senduny, F.F.; Al-Majid, A.M.; Elshaier, Y.A.; Badria, F.A.; Barakat, A. Synthesis of new thiazolopyrrolidine-(spirooxindole) tethered to 3-acylindole as anticancer agents. Bioorg. Chem. 2019, 82, 423-430. [CrossRef]

30. Barakat, A.; Islam, M.S.; Al Majid, A.M.; Ghawas, H.M.; El-Senduny, F.F.; Badria, F.A.; Elshaier, Y.A.M.M.; Ghabbourfg, H.A. Substituted spirooxindole derivatives as potent anticancer agents through inhibition of phosphodiesterase 1. RSC Adv. 2018, 8, 14335. [CrossRef]

31. Lotfy, G.; El, S.H.; Said, M.M.; Aziz, Y.M.A.; Al-Dhfyan, A.; Al-Majid, A.M.; Barakat, A. Regio- and stereoselective synthesis of novel spiro-oxindole via 1,3-dipolar cycloaddition reaction. Anti-cancer and molecular docking studies. J. Photochem. Photobiol. B 2018, 180, 98-108. [CrossRef] [PubMed]

32. Barakat, A.; Soliman, S.M.; Al-majid, A.M.; Ali, M.; Islam, M.S.; Elshaier, Y.A.M.M.; Ghabbour, H.A. Regioselective synthesis of novel spiro-oxindole constructed with pyrrolidine/thioxothiazolidin-4-one derivatives: X-ray crystal structures, Hirshfeld surface analysis, DFT, docking and antimicrobial studies. J. Mol. Struc. 2018, 1152, 101-114. [CrossRef]

33. Lotfy, G.; Said, M.M.; El, S.H.; Al-Dhfyan, A.; Aziz, Y.M.A.; Barakat, A. Synthesis of new spirooxindole-pyrrolothiazoles derivatives: Anti-cancer activity and molecular docking. Bioorg. Med. Chem. 2017, 25, 1514-1523. [CrossRef]

34. Al-Majid, A.M.; Soliman, S.M.; Haukka, M.; Ali, M.; Islam, M.S.; Shaik, M.R.; Barakat, A. Design, construction, and characterization of a new regioisomer and diastereomer material based on the spirooxindole scaffold incorporating a sulphone function. Symmetry 2020, 12, 1337. [CrossRef]

35. Nammalwar, B.; Darrell, B.K.; Bunce, R.A. SHetA2-A Mini review of a promising anticancer drug. JSM Chem. 2013, 1005, 1-6.

36. Zhang, D.; Ji, X.; Gao, R.; Wang, H.; Meng, S.; Zhong, Z.; Li, Y.; Jiang, J.; Li, Z. Synthesis and antiviral activities of a novel class of thioflavone and flavonoid analogues. Acta. Pharmacol. Sin. B 2012, 2, 575-580. [CrossRef]

37. Yoneya, T.; Taniguchi, K.; Nakamura, R.; Tsunenari, T.; Ohizumi, I.; Kanbe, Y.; Morikawa, K.; Kaiho, S.-I.; Yamada-Okabe, H. Thiochroman derivative $\mathrm{CH} 4986399$, A new nonsteroidal estrogen receptor down-regulator is effective in breast cancer models. Anticancer. Res. 2010, 30, 873-878.

38. Nussbaumer, P.; Lehr, P.; Billich, A. 2-Substituted 4-(thio)chromenone 6-osulfamates: Potent inhibitors of human steroid sulfatase. J. Med. Chem. 2002, 45, 4310-4320. [CrossRef] [PubMed]

39. Nussbaumer, P.; Winiski, A.P.; Billich, A. Estrogenic potential of 2-alkyl-4-(thio)chromenone 6-O-sulfamates: Potent inhibitors of human steroid sulfatase. J. Med. Chem. 2003, 46, 5091-5094. [CrossRef]

40. Horvath, A.; Nussbaumer, P.; Wolff, B.; Billich, A. 2-(1- Adamantyl)-4-(thio)chromenone-6-carboxylic acids: Potent reversible inhibitors of human steroid sulfatase. J. Med. Chem. 2004, 47, 4268-4276. [CrossRef] [PubMed]

41. De Bernardis, J.F.; Arendsen, D.L.; Zelle, R.E. Aminomethyl-chroman and -thiochroman compounds. U.S. Patent 5185364, 1993.

42. Hadda, T.B.; Kerbal, A.; Bennani, B.; Houari, G.A.; Daoudi, M.; Leite, A.C.L.; Masand, V.H.; Jawarkar, R.D.; Charrouf, Z. Molecular drug design, synthesis and pharmacophore site identification of spiroheterocyclic compounds: Trypanosoma cruzi inhibiting studies. Med. Chem. Res. 2013, 22, 57-69. [CrossRef]

43. Nakib, T.A.; Bezjak, V.; Meeganz, M.J.; Chandy, R. Synthesis and antifungal activity of some 3-benzylidenechroman-4-ones, 3-benzylidenethiochroman-4-ones and 2- benzylidene-1-tetralones. Eur. J. Med. Chem. 1990, 25, 455-462. [CrossRef]

44. Pavlovska, T.L.; Redkin, R.G.; Lipson, V.V.; Atamanuk, D.V. Molecular diversity of spirooxindoles. Synthesis and biological activity. Mol. Divers. 2016, 20, 299-344. [CrossRef]

45. Bora, D.; Kaushal, A.; Shankaraiah, N. Anticancer potential of spirocompounds in medicinal chemistry: A pentennial expedition. Eur. J. Med. Chem. 2021, 215, 113263. [CrossRef] [PubMed]

46. Miyake, F.Y.; Yakushijin, K.; Horne, D.A. Preparation and synthetic applications of 2-halotryptamines: Synthesis of elacomine and isoelacomine. Org. Lett. 2004, 6, 711-713. [CrossRef]

47. Finch, N.; Taylor, W.I. Oxidative transformations of indole alkaloids. I. The preparation of oxindoles from yohimbine; the structures and partial syntheses of mitraphylline, rhyncophylline and corynoxeine. J. Am. Chem. Soc. 1962, 84, 1318-1320. [CrossRef]

48. Overman, L.E.; Rosen, M.D. Total synthesis of (-)-spirotryprostatin B and three stereoisomers. Angew. Chem. Int. Ed. 2000, 39, 4596-4599. [CrossRef]

49. Saranya, P.V.; Neetha, M.; Aneeja, T.; Anilkumar, G. Transition metal-catalyzed synthesis of spirooxindoles. RSC Adv. 2021, 11, 7146-7179. [CrossRef]

50. Ghandi, M.; Taheri, A.; Abbasi, A. A facile synthesis of chromeno[3,4-c]spiropyrrolidine-oxindoles via 1,3-dipolar cycloadditions. Tetrahedron 2010, 66, 6744-6748. [CrossRef] 
51. Zhao, K.; Zhi, Y.; Shu, T.; Valkonen, A.; Rissanen, K.; Enders, D. Organocatalytic domino Oxa-Michael/1,6-addition reactions: Asymmetric synthesis of chromans bearing oxindole scaffolds. Angew. Chem. Int. Ed. 2016, 128, 12283-12287. [CrossRef]

52. Mao, H.; Lin, A.; Tang, Y.; Shi, Y.; Hu, H.; Cheng, Y.; Zhu, C. Organocatalytic oxa/aza-Michael-Michael cascade strategy for the construction of spiro [chroman/tetrahydroquinoline-3, 3'-oxindole] scaffolds. Org. Lett. 2013, 15, 4062-4065. [CrossRef]

53. Arai, T.; Miyazaki, T.; Ogawa, H.; Masu, H. PyBidine-Ni (OAc) 2-catalyzed Michael/Aldol reaction of methyleneindolinones and thiosalicylaldehydes for stereochemically divergent thiochromanyl-spirooxindoles. Org. Lett. 2016, 18, 5824-5827. [CrossRef] [PubMed]

54. Rodriguez, J.; Bonne, D. Stereoselective Multiple Bond-Forming Transformations in Organic Synthesis; John, W., Sons, H., Eds.; John Wiley \& Sons: Hoboken, NJ, USA, 2015.

55. Mannerström, M.; Toimela, T.; Sarkanen, J.-R.; Heinonen, T. Human BJ Fibroblasts is an alternative to mouse BALB/c 3 T3 cells in in vitro neutral red uptake assay. Basic Clin. Pharmacol. Toxicol. 2017, 121, 109-115. [CrossRef]

56. Price, P.; McMillan1, T.J. Use of the tetrazolium assay in measuring the response of human tumor cells to ionizing radiation. Cancer Res. 1990, 50, 1392-1396. Available online: https:/ / cancerres.aacrjournals.org/content/canres/50/5/1392.full.pdf (accessed on 1 June 2020). [PubMed]

57. Scudiero, D.A.; Shoemaker, R.H.; Paull, K.D.; Monks, A.; Tierney, S.; Nofziger, T.H.; Currens, M.J.; Seniff, D.; Boyd, M.R. Evaluation of a soluble tetrazolium/formazan assay for cell growth and drug sensitivity in culture using human and other tumor cell lines. Cancer Res. 1988, 48, 4827-4833. [PubMed]

58. Mosmann, T. Rapid colorimetric assay for cellular growth and survival: Application to proliferation and cytotoxicity assays. J. Immunol. Methods 1983, 65, 55-63. [CrossRef]

59. Comşa, Ş.; Cimpean, A.M.; Raica, M. The story of MCF-7 breast cancer cell line: 40 years of experience in research. Anticancer Res. 2015, 35, 3147-3154. [PubMed]

60. Mielczarek, L.; Krug, P.; Mazur, M.; Milczarek, M.; Chilmonczyk, Z.; Wiktorska, K. In the triple-negative breast cancer MDAMB-231 cell line, sulforaphane enhances the intracellular accumulation and anticancer action of doxorubicin encapsulated in liposomes. Int. J. Pharm. 2019, 558, 311-318. [CrossRef]

61. Zhao, D.; Sun, B.; Ren, J.; Li, F.; Song, S.; Lv, X.; Hao, C.; Cheng, M. Synthesis and biological evaluation of 3-phenyl-3-aryl carboxamido propanoic acid derivatives as small molecule inhibitors of retinoic acid 4-hydroxylase (CYP26A1). Bioorg. Med. Chem. 2015, 23, 1356-1365. [CrossRef]

62. Foye, W.O.; Lemke, T.L.; Williams, D.A. Principles of Medicinal Chemistry, 4th ed. williams \& wilkins: Philadelphia, PA, USA, 2002; p. 822. 